\title{
LA RESPONSABILIDAD CIVIL DE LOS SUMINISTRADORES ${ }^{1}$
}

\author{
Ricardo de Angel Yágüez \\ Catedrático de Derecho civil de la Universidad de Deusto. Bilbao, España
}

\begin{abstract}
Sumario: I. Delimitación del objeto de esta ponencia. 1. El concepto de suministrador, a estos efectos. 2. Significado, en este caso, de la expresión «responsabilidad civil». 3. Suministrador, en general, y «suministrador final». 4. A qué daños nos referimos. II. Servicios y productos. Una distinción no siempre clara. 1. Planteamiento. 2. Lo que sugiere la Ley de responsabilidad civil por daños causados por productos defectuosos, en relación con las opiniones doctrinales al respecto. 3. Casuística de la jurisprudencia. 4. Los casos especiales del gas y de la electricidad. 5. La acumulación de acciones, como posible fórmula procesal. III. Responsabilidad del suministrador de servicios. 1. Consideraciones generales. 2. El régimen de responsabilidad del Código civil. 3. El régimen especial de la Ley de consumidores y usuarios. IV. Responsabilidad del suministrador de productos. 1. Inaplicabilidad de la Ley de consumidores y usuarios a casos de daños causados por productos defectuosos. La disposición final primera de la Ley de productos defectuosos. 2. Esa inaplicabilidad ha sido declarada también por el Tribunal de Justicia de las Comunidades Europeas. La Directiva de 25 de julio de 1985 no es «de mínimos». 3. El «sistema» de responsabilidad de la Ley de productos defectuosos. 4. Menciones legales de la responsabilidad del suministrador. 5. Las dos vertientes en las que puede manifestarse la responsabilidad del suministrador de productos, una en el marco de la Ley y otra en el del régimen general de responsabilidad del Código civil.
\end{abstract}

\section{Delimitación del objeto de esta ponencia}

La intervención que se me ha encomendado lleva por título el de «La responsabilidad civil de los suministradores».

Aunque las materias objeto de las demás ponencias no plantean problemas de colisión con la que me corresponde, se hace imprescindible determinar el marco de mi intervención; esto es, se impone una cuestión previa de delimitación.

1 Este trabajo es el texto extenso de la ponencia desarrollada por el autor en las X Jornadas de responsabilidad civil y seguros, organizadas por el Colegio de Abogados de Zaragoza. Días 4 y 5 de febrero de 2005. 
Pero debo advertir que las consideraciones de este primer capítulo no responden sólo al propósito de definir el ámbito de mi aportación, porque eso sería únicamente ceder a razones estéticas o de mera disciplina del expositor, sino que encierran en sí mismas una parte importante de la ponencia. Porque, en efecto, determinar sus límites es una manera de afrontar los muchos problemas previos que el título de la conferencia sugiere.

\section{El concepto de suministrador, a estos efectos}

La palabra «suministrador»-que, a estos efectos, nada tiene que ver con el nombre que se atribuye a una de las partes del contrato que llamamos suministro (en definitiva, una venta «fraccionada») - ha adquirido carta de naturaleza en nuestra terminología jurídica, queriéndose identificar con ella a quien proporciona (por ahora procede utilizar este verbo tan poco jurídico) productos o servicios a un consumidor.

Es decir, el término suministrador se ha afincado en nuestro modo de hablar en el marco del que conocemos como Derecho del consumo. $\mathrm{O}$, dicho de otro modo, dentro del conjunto de instrumentos encaminados a tutelar jurídicamente a los consumidores y usuarios.

Así, aunque la palabra suministrador sugiera a primera vista la idea de «cosas», no debe olvidarse que, según el Diccionario de la Real Academia, suministrador significa «que suministra»; y que suministrar quiere decir «proveer a uno de algo que necesita».

La más reciente Ley, de entre las importantes, que nuestro ordenamiento jurídico conoce en materia de consumo, esto es, la de 6 de julio de 1994, de responsabilidad civil por los daños causados por productos defectuosos (en adelante, para simplificar, Ley de productos defectuosos o LRCPD), utiliza la palabra suministrador en un par de ocasiones, sin perjuicio de que además haga uso de la fórmula verbal «hubiere suministrado».

Esto movería a pensar que mi ponencia tiene que limitarse, en efecto, a quien suministra un producto.

A la misma idea podría conducir el Real Decreto 1801/2003, de 26 de diciembre, sobre seguridad general de los productos. Porque, como veremos, una de las más significativas parcelas de responsabilidad del suministrador es la constituida por el incumplimiento de sus obligaciones de seguridad.

No obstante, debe tenerse presente también que otra Ley de nuestro ordenamiento jurídico, la general para la defensa de los consumidores y usuarios, de 24 de julio de 1984 (en lo sucesivo, también para facilitar la exposición, Ley de consumidores y usuarios o LCU), per- 
mite considerar suministrador a quien dispensa, presta o proporciona servicios.

Aunque la Ley de consumidores y usuarios no es precisamente un dechado de virtudes en materia terminológica, su artículo 27.1.A), al referirse al «fabricante, importador, vendedor o suministrador de productos o servicios», permite llamar así, suministrador, a quien compromete una prestación de hacer (lo característico de los servicios); no una de dar, que es lo definidor del mundo de los productos ${ }^{2}$.

\section{Significado, en este caso, de la expresión «responsabilidad civil»}

También suscita reflexiones previas, con marcado contenido de fondo (es decir, mucho más allá de lo que serían simples objetivos de circunscribir el objeto de mi intervención), la circunstancia de que su título hable de responsabilidad civil.

El adjetivo civil puede ser interpretado de dos maneras.

Una primera, que es la que me parece que está en el ánimo de la organización de estas Jornadas, es la de dejar sentado que hablamos de responsabilidad del suministrador en el plano civil, como forma de excluir otro orden de responsabilidades; señaladamente, la penal.

Pero existe una segunda interpretación, de la que voy a ocuparme ya aquí porque toca a uno de los más vidriosos problemas de la responsabilidad del suministrador.

Me refiero a la posibilidad de entender que la expresión responsabilidad civil se utiliza en el título de la ponencia como equivalente a responsabilidad extracontractual. Lo que significaría dejar fuera el ámbito de la que, como distinta, llamamos responsabilidad contractual ${ }^{3}$.

Lo que acabo de decir es sólo una excusa, porque, en primer lugar, parece claro que la rúbrica de mi ponencia quiere referirse a toda responsabilidad en el plano civil, no sólo a la que tradicionalmente conocemos como responsabilidad civil, esto es, la extracontractual.

2 Es ese artículo 27 el más significativo en este aspecto terminológico que me ocupa, porque aunque también el artículo 11.2 utiliza la palabra suministrador, el conjunto de la norma lleva inequívocamente al sector de los productos. Lo mismo sucede en la disposición adicional primera, introducida por la Ley de 13 de abril de 1998, sobre condiciones generales de la contratación; en ella, número 25, la palabra suministrador sugiere también, creo que sin lugar a dudas, la idea de quien provee de productos (obsérvese que se habla de «obligaciones o prestaciones propias del productor o suministrador»).

3 Subyace a esta cuestión la de si, como hace autorizada doctrina, puede hablarse de una responsabilidad civil contractual. No es momento de entrar en este extremo, pero tengo mis reservas respecto a esa denominación. 
En segundo término, es justamente en relación con la responsabilidad del suministrador donde con más claridad se aprecian las fragilidades de la distinción entre responsabilidad contractual y extracontractual.

No puede olvidarse que en la raíz de las modernas (y de las que no lo son tanto) tendencias doctrinales, legislativas y jurisprudenciales sobre la responsabilidad por productos y servicios, sobre todo en la de productos, se encuentra el peliagudo problema de cómo articular la responsabilidad, y qué tipo de responsabilidad, en el caso de que el daño se hubiese sufrido por quien no fue parte en el contrato con el primer suministrador, esto es, el fabricante.

No está de más recordar que fue en este terreno en el que, primero en Estados Unidos, y luego en Inglaterra, se arbitraron por la jurisprudencia soluciones encaminadas a una mayor protección de los consumidores. Aparentemente encorsetados los juristas por ciertos dogmas clásicos, como el de la privity of contract (el principio de relatividad de los contratos en el Derecho continental europeo, artículo 1.257 de nuestro Código civil), diversas formulaciones más o menos ingeniosas (pero un tanto forzadas, como la del collateral contract o la de la extended vertical privity) condujeron a resoluciones judiciales por cuya virtud era condenado el fabricante aunque no hubiese mantenido relación contractual con el cliente, consumidor o destinatario final. Se trataba de poder imputar responsabilidad tanto a los fabricantes como a todos los participantes en las operaciones ulteriores de venta, incluyendo a los intermediarios intervinientes en el proceso de distribución.

Se recordará que la «falacia» de la privity of contract fue rechazada en Inglaterra en 1932 en el famoso caso Donoghue v. Stevenson (en una botella de cerveza se encontraron restos descompuestos de un caracol). Se admitió que la demandante pudiese reclamar al fabricante de la cerveza en base al tort of negligence por daño personal y shock, aunque aquélla no había contratado con éste.

Parecido problema se encuentra cuando hablamos de la responsabilidad del suministrador final.

No está de más recordar que, en la doctrina francesa, y tratando de ilustrar las incongruencias a las que puede conducir la distinción entre responsabilidad contractual y extracontractual, la maestra VINEY proponía ejemplos, extraídos de la jurisprudencia de su país, como los por ella llamados el de la «botella que explota», el del «resbalón en el suelo» y el de las «sorpresas que reserva la entrada en una estación». Al referirse al primero, VINEY aludía al caso de la explosión de una botella en un supermercado; si daña a un cliente que pasaba por allí, la res- 
ponsabilidad del comerciante es extracontractual; pero si la botella explota en las manos de un cliente que la ha tomado de las estanterías con intención de comprarla, la responsabilidad del propietario del supermercado se plantea sobre la base de una obligación contractual de seguridad 4 .

En nuestro Derecho, dos circunstancias han venido a ahondar una de ellas, y la otra a difuminar, el significado de las dos formas de responsabilidad (ambas civiles en el sentido más amplio del adjetivo) que nos ocupan.

De un lado, en el primer sentido, la persistente doctrina jurisprudencial de que para que la responsabilidad contractual opere con exclusión de la extracontractual no es bastante que haya un contrato entre las partes, sino que se requiere para ello que la realización del hecho dañoso acontezca dentro de la rigurosa órbita de lo pactado y como preciso desarrollo del contenido negocial, pues si se trata de negligencia extraña a lo que constituye propiamente materia del contrato, desplegará sus efectos propios la responsabilidad aquiliana.

Pero por otra parte, en sentido contrario, la también doctrina jurisprudencial de la llamada unidad de la culpa civil viene a «disolver» muchas de las consecuencias prácticas de la distinción entre contractual y extracontractual, ofreciendo al perjudicado, en principio, un generoso abanico de posibilidades de reclamación.

Pero, por ahora, basta formular estas consideraciones, sobre las que volveré en parte al ocuparme, por separado, del suministrador de productos y del que lo es de servicios.

4 No es necesario insistir en el quebradero de cabeza que resulta del intento de establecer una «frontera exacta» entre las dos formas de responsabilidad que nos ocupan. Opino que la distinción tiene fundamento, siendo sus dos términos (contractual y extracontractual) algo más que categorías meramente conceptuales, de exclusivo valor académico, e incluso diríase pedagógico. No obstante, como señalo en el texto, es evidente que razonar con esos dos términos como si fueran compartimentos estancos puede conducir a desenlaces poco lógicos e incluso absurdos. Me viene a la mente el jocoso comentario que, también en Francia, hizo ESMEIN del caso llamado «caída en una escalera». Según si la víctima es un arrendatario o un extraño, la responsabilidad del propietario se califica como contractual o delictual. Las posibilidades de indemnización de la víctima pueden ser radicalmente diferentes, en atención a la llamada «obligación contractual de seguridad» que corresponde al arrendador respecto al arrendatario. Creo - decía el autor- que es inaceptable hacer responsable al propietario de forma diferente en relación con el arrendatario que en lo que se refiere a terceros que se caen en la escalera; aquél debe mantenerla en buen estado para con todos los que están en condiciones de utilizarla. Decía EsmeIn que dudaba de una doctrina jurídica que él no pudiera hacer entender a los justiciables. Palabras estas últimas, por cierto, que creo que tendrían que ser regla de oro del jurista en todo caso. 
3. Suministrador, en general, $y$ «suministrador final»

Una tercera cuestión se impone.

Esta ponencia se refiere a responsabilidad del suministrador. Pero es necesario, sobre todo si lo es de productos, definir de qué suministrador hablamos.

En efecto, si, como de ordinario ocurre, el producto elaborado por el fabricante es objeto de una «cadena» de distribución, es menester determinar si hablamos de todo suministrador (a grandes rasgos, y para simplificar, el fabricante mismo, el mayorista o comercializador y el que «distribuye» el producto en el último eslabón de la cadena, esto es, el llamado suministrador final ${ }^{5}$ ); o si, por el contrario, nos referimos sólo al último suministrador o suministrador final.

La cuestión, como veremos, no es irrelevante. Al contrario, fundamental a efectos de poner en contraste las reglas de la Ley de consumidores y usuarios con las de la Ley de productos defectuosos.

Este mismo extremo, de qué suministrador hablamos, lleva consigo preguntarse sobre a qué perjudicado nos estamos refiriendo, puesto que la responsabilidad en el orden civil presupone inexcusablemente la existencia de un daño. Es necesario, pues, determinar quién lo ha sufrido.

También aquí, me remito al ulterior desarrollo de esta ponencia.

\section{A qué daño nos referimos}

Por fin, y enlazando con la obvia manifestación de que la responsabilidad civil presupone un daño, resulta obligado plantearse la cuestión acerca de qué daño hemos de tomar en consideración.

Es claro por qué digo esto.

En primer lugar, hay que tener en cuenta, sobre todo en punto a suministro de productos, la diferencia entre daños del producto y daños por el producto, esto es, los causados como consecuencia de ser éste defectuoso.

En segundo término, y en relación con la segunda de las hipótesis que acabo de mencionar (daños por el producto), es inexcusable preguntarse si la responsabilidad es por todos los daños (se trataría del concepto omnicomprensivo del artículo 1.106 del Código civil, «daños y perjuicios» entendidos como daño emergente y lucro cesante - pérdida sufrida y ganancia dejada de obtener-, incluidos los «daños mora-

5 En este último caso, y aunque la precisión no tenga mayor importancia a efectos de daños por el objeto (como distintos de daños en el objeto), la fórmula contractual típica será la compraventa civil, frente al carácter de mercantil propio de las compraventas «intermedias» en la metafórica cadena. 
les»); o si, por el contrario, hablamos de algunos daños; lo que significaría, en función de un determinado régimen legal, dejar «fuera» otros posibles daños.

Es claro que el principio de «reparación íntegra» que deriva del artículo 1.101 del Código civil para la responsabilidad contractual y del 1.902 para la extracontractual, entraña la consecuencia de que la víctima o perjudicado debe ser indemnizado en la totalidad de los daños y perjuicios que, según cada caso, sufriere.

No obstante, la distinta regulación contenida en la Ley de consumidores y usuarios y en la de productos defectuosos, con el trasfondo del régimen general del Código civil (artículo 4.3), implica la necesidad de hacer en este punto los necesarios distingos. Es lo que se hará más adelante, en relación con la doble hipótesis de responsabilidad por servicios y por productos.

\section{Servicios y productos. Una distinción no siempre clara}

\section{Planteamiento}

Por imperativo del propio título de esta ponencia, y como consecuencia del muy diferente régimen legal aplicable a una y otra hipótesis, se hace necesario desarrollar por separado el régimen de la responsabilidad por servicios y de la responsabilidad por productos 6 .

No obstante, aquí empiezan en ocasiones los problemas, porque no siempre es fácil, en presencia del caso concreto, determinar cuándo estamos en uno o en otro terreno.

Los casos extremos (es decir, los que a veces solemos llamar casos fáciles) no dan lugar a dudas: la compra de una lata de conserva, por proponer un ejemplo elemental; o, en el otro extremo, la limpieza de una prenda en una tintorería.

Pero, como decía y todos sabemos, las cosas no suelen ser tan fáciles a efectos de calificación.

En efecto, hay productos con servicio. Sería el caso de la máquina que el suministrador se obliga a instalar; o del plaguicida que el suministrador se obliga a aplicarlo sobre cuya aplicación queda obligado a dar instrucciones; o el de cualquier producto en el que el suministrador compromete un servicio de postventa.

Y, por otro lado, hay servicios con productos. Por citar también aquí casos de la jurisprudencia, podemos pensar en el «servicio» de tra-

\footnotetext{
${ }^{6}$ Sólo nos referimos al caso del suministrador, para ser fieles al objeto de este trabajo.
} 
tamiento capilar en el que debe aplicarse un determinado producto; o en el sanitario (en la acepción más amplia) de implantación de un dispositivo intrauterino.

\section{Lo que sugiere la Ley de responsabilidad civil por daños causados por productos defectuosos, en relación con las opiniones doctrinales al respecto}

Siguiendo la línea de la Directiva comunitaria, la Ley española de responsabilidad civil por daños causados por productos defectuosos se refiere sólo a los daños causados por productos defectuosos, esto es, no alcanza a los daños derivados de servicios defectuosos. Esto contrasta con la orientación de la LCU, que en su propósito de proteger o tutelar a todo tipo de consumidores, o sea, no sólo a los que lo son en sentido estricto (de productos), sino también a quienes reciben servicios de terceros, incluye en su ámbito tanto los daños causados por productos como los resultantes de la dispensación de servicios.

No procede extenderse demasiado en las razones por las que la Directiva excluyó de su ámbito los servicios, pero sí hacer un resumen de las que la doctrina ha expuesto. En este sentido, creo que tienen sentido los siguientes argumentos: en primer lugar, una diferencia relevante entre el fabricante de bienes y el prestador de servicios radica en que el segundo está de ordinario ligado contractualmente con el receptor de la prestación: los problemas que surgen en la relación entre las partes se resuelven normalmente, al contrario de lo que ocurre en la hipótesis de responsabilidad del fabricante de bienes, en el plano contractual, donde - según opinión general- el demandante encuentra menores dificultades probatorias en comparación con las que tiene ante un fabricante «lejano», dominus de una actividad productiva que el perjudicado desconoce totalmente; en segundo lugar, la extrema variedad y diversidad de relaciones que pueden incluirse en la rúbrica de «prestación de servicios» no permite la creación de reglas generales en un único sentido: la responsabilidad del porteador, en el transporte, se tiñe de connotaciones objetivas totalmente impensables, por ejemplo, en la mayor parte de los casos de ejercicio de una actividad intelectual; por otro lado, la prestación de un servicio no comporta, de ordinario, los problemas de seguridad del consumidor, que tanta importancia han tenido en el nacimiento y desarrollo del concepto de responsabilidad del fabricante; por último, en numerosos supuestos de servicios destinados a la empresa, las técnicas elaboradas en función de la protección de los intereses económico-patrimoniales de los consumidores no parecen adecuadas para una correcta solución de los problemas. 
Desde luego, la frontera entre «productos»y «servicios» no es siempre nítida, como se puso de relieve por especialistas de varios países en el Coloquio "Liability for services rendered», celebrado en Lausana los días 1 a 3 de setiembre de 1993 bajo la organización de The International Association of Legal Sciences. Por su parte, un «clásico» en materia de Derecho de daños (ATIYAH $)^{7}$ señala que el hecho de que la Directiva se aplique sólo a productos, no a servicios, es explicable en términos históricos, pero a su juicio no encuentra razones fundadas. Y aún más, añade, la norma comunitaria no traza una clara distinción entre productos y servicios, porque las reclamaciones basadas en que los productos son defectuosos constituyen, en el fondo, reclamaciones cuyo origen está en que alguien ha llevado a cabo un servicio (diseñar el objeto, supervisarlo, etc.) de forma incorrecta.

Un problema de particular importancia, derivado de la diferencia - tan difusa - entre producto y servicio se plantea en el caso en que en la prestación de este último se causa un daño como consecuencia de un producto utilizado en el curso de la misma.

También se suscita esta cuestión a la luz de ejemplos extraídos de la jurisprudencia norteamericana: instrumentos usados durante una intervención quirúrgica, como el caso de una crema antibactérica altamente inflamable (sin que el fabricante se hubiese cuidado de advertirlo en las instrucciones) que, derramada sobre el cuerpo de la paciente antes de la operación, da lugar a un fuego al entrar en contacto con otros elementos; instrumento quirúrgico de alta precisión, pero fabricado incorrectamente, que, empleado durante una operación de columna vertebral, causa daños graves e irreversibles al paciente; inyección de un anestésico con rotura de la aguja de la jeringa, que queda clavada en la boca del enfermo. En tales casos, se ha tratado de obtener la indemnización directamente del prestador de servicios, invocándose la responsabilidad objetiva (strict liability) por defecto del producto, de forma similar a la de la responsabilidad del fabricante.

Se advierte que en esos casos se daba por supuesta la responsabilidad del fabricante o, al menos, la posibilidad de citarlo a juicio, pero a la vez se planteaba la pregunta de si podía considerarse que el fabricante era el único responsable o, por el contrario, si esa responsabilidad podía predicarse también del prestador del servicio; dicho de otro modo, si al perjudicado le era posible actuar sólo contra este último, sin perjuicio de que a su vez el prestador del servicio pudiera dirigirse luego contra el fabricante. Y a este respecto, procede indicar que la ju-

7 En edición actualizada por CANE, P. (Atiyah's Accidents, Compensation and the

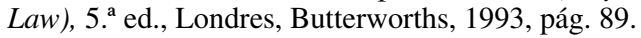


risprudencia estadounidense se ha mostrado contraria a admitir que el prestador de servicios pueda ser considerado responsable (por el concepto de strict liability, se entiende, no sobre la base de la culpa) por no haber comprobado el imperfecto funcionamiento del objeto; a no ser que el defecto fuera reconocible con el mero uso de la diligencia profesional. Esta tendencia sólo ha tenido la excepción del caso de responsabilidad (objetiva) del hospital, institución profesionalmente organizada para el desarrollo de servicios sanitarios y, en concreto, de operaciones quirúrgicas; se explica de este modo la adopción de un criterio de responsabilidad objetiva: al menos si se demuestra que una prueba previa del producto habría podido advertir de su defectuosidad ${ }^{8}$.

CLARK $^{9}$, que hace una interesante comparación entre los criterios norteamericanos y británicos al respecto, pone de manifiesto que en los tribunales de Estados Unidos ha venido siendo objeto de enconadas discusiones la distinción entre producto y servicio en numerosos supuestos. La diferencia tiene allí también notable significado, porque los casos de responsabilidad por productos se juzgan con criterios de responsabilidad objetiva, en virtud de la sección 402A del Restatement (Second) on Torts. Menciona el autor las dificultades y diversidad de criterios característicos de los casos de suministro de sangre humana o productos de ella derivados, de suministro de «servicios farmacéuticos»y de suministro de «información».

En cuanto al primero de ellos, aunque hay jurisprudencia contradictoria, la tendencia es a considerar que se trata de un servicio, no de venta de un producto.

Respecto a los servicios de farmacia, también en ellos existe discrepancia, aunque la opinión dominante se inclina por entender (para excluir la responsabilidad objetiva del farmacéutico) que existe diferencia entre él y cualquier otro comerciante, ya que el primero es sobre todo un profesional; así se resolvió en el caso Murphy v. R.R. Squibb and Sons Inc., del Tribunal Supremo de California ${ }^{10}$.

8 Se cita al respecto por los autores norteamericanos el caso Grubb v. Albert Einstein Medical Center, en que el Tribunal Supremo de Pennsylvania condenó al hospital con criterio de strict liability porque, como consecuencia de la defectuosidad de un producto, el paciente había quedado parapléjico. Se ocupa también de este problema VALSECCHI, A., Commentario d. P.R. 24 maggio 1988, n. 224, sulla disciplina del danno causato da prodotti difettosi, en Responsabilità del produtore e nuove forme di tutela del consumatore (a cargo de DRAETTA y VACCÀ), Milán, EGEA, 1993, págs. 143-145, que cita casos dudosos de responsabilidad de empresas que explotan negocios de lavado de prendas en su modalidad de self service.

9 Clark, A., Product Liability, Londres, Sweet \& Maxwell, 1989, págs. 61-65.

10 Si bien ClARK, loc. cit., expresa sus dudas, por entender que cuando el farmacéutico suministra una medicina, su actividad es más de «venta» que de «asesoramiento» 0 «consejo». 
Por lo que respecta al «suministro de información», como advierte el mismo autor, los problemas aumentan cuando se trata de una información de alta tecnología: por ejemplo, se pregunta: ¿responderán con criterios de responsabilidad objetiva los fabricantes de software informático como «suministradores» de un producto? En algunos casos, también en Estados Unidos, se ha adoptado el sistema de responsabilidad objetiva en casos de información "producida en masa», es decir, no realizada «a la medida del cliente»; por ejemplo, se siguió el criterio de strict liability en el caso Fluor Corp. v. Jeppeson Inc. (California, 1985), en el que un mapa de aproximación a un aeropuerto no indicaba la existencia de una colina que era el punto más elevado del lugar: prevaleció el argumento de la elaboración «masiva» de esos mapas o planos y la consideración de que al decidir si una cosa es o no un producto, deben entrar en juego razones de prudencia y en concreto la necesidad de ofrecer adecuada protección respecto a los defectos de fabricación.

Suministran también interesante información sobre esta, a veces, complicada distinción entre productos y servicios, con una rica casuística norteamericana, SPEISER et al. ${ }^{11}$, que propugnan la exclusión, únicamente, de los «servicios profesionales»; EPSTEIN ${ }^{12}$, para quien sólo los «meros» suministradores de servicios deben quedar fuera del marco de la strict liability; y DOBBS ${ }^{13}$, que pone de relieve la dificultad en la calificación en lo que él denomina «transacciones híbridas» ${ }^{14}$.

En nuestra doctrina, PARRA LUCAN ${ }^{15}$ se planteó esta cuestión a la luz de la LCU, aunque a estos efectos la diferencia no era significativa: casi exclusivamente en cuanto a la aplicación del capítulo VIII de dicha Ley. Y en lo que respecta a la Directiva, la autora dijo que, a su entender, si bien no será posible reclamar al amparo de la norma comunitaria por la defectuosa prestación de un servicio, sí que hay que reconocer

11 Speiser, S.M., Krause, C.F., y Gans, A.W., The American Law of Torts, vol. 5 y vol. 6, Nueva York,, Clark, Boardman, Callaghan, 1988 y 1989, respectivamente. En concreto, en vol. 6, págs. 373-386.

12 EpsteIn, R.A., Cases and Materials on Torts, 5. ${ }^{a}$ ed., s.1., Little, Brown and Company, 1990, págs. 659 ss.

${ }_{13}$ DobBs, D.D., Torts and Compensation (Personal accountability and social responsibility for injury), 2. a ed., St. Paul, Minn., West Publishing Co., 1993, págs. 698 ss.

${ }_{14}$ Es muy característico el caso que, entre otros, cita. Fue el pleito Newmark v. Gimbel's Inc. (Tribunal Supremo de Nueva Jersey, 1969), en que la demandante había sufrido quemaduras durante la aplicación de un tratamiento para su cabello; un dermatólogo informó que había contraído dermatitis como consecuencia de la aplicación de una solución para una permanente. El tribunal consideró que la demandada había llevado a cabo un servicio, no la venta de un producto.

15 Parra LuCÁn, M.A., Daños por productos y protección del consumidor, Barcelona, José María Bosch, 1990, págs. 347-350 y 484-485. 
que la víctima de un daño producido por un bien suministrado con ocasión de la prestación de un servicio podrá reclamar sobre la base del sistema de responsabilidad contenido en la Directiva. En una obra posterior $^{16}$, y refiriéndose en concreto al servicio sanitario, la autora dice: "La víctima de un daño causado por un producto defectuoso suministrado con ocasión de la prestación de un servicio sanitario podrá optar: i) por ejercitar las acciones derivadas de la responsabilidad por productos; ii) por ejercitar las acciones derivadas de la prestación de la asistencia sanitaria; iii) por ejercitar, de forma acumulada, ambas.»

Por su parte, ALCOVER GARAU ${ }^{17}$ considera que entran dentro del ámbito de la Directiva «los bienes suministrados a la víctima como parte de una relación de servicios».

A mi juicio, conceptualmente hay que distinguir varias hipótesis: en primer término, la de un producto que - según sostiene el demandante - ha sido utilizado o aplicado incorrectamente, con independencia de que sea o no defectuoso. En este caso, el perjudicado puede seguir la vía propia de la responsabilidad por servicios defectuosos, es decir, la que brinda la LCU, que por cierto llevará de ordinario a soluciones prácticas no muy diferentes de las que se alcanzarían con la Ley de responsabilidad por productos.

Puede ocurrir, segunda hipótesis, que en el juicio a que se refiere el supuesto anterior se demuestre que la aplicación fue correcta o adecuada, pero el producto era defectuoso. En este caso, creo que la inversión de la carga de la prueba, que es el régimen general de responsabilidad de la LCU, podría conducir a la absolución del demandado si acredita que, dadas las circunstancias del caso, no constituyó negligencia por su parte no haber conocido el carácter defectuoso del producto. A no ser, claro está, que se trate de los servicios que de acuerdo con el artículo 28 de la LCU están gobernados por un criterio de responsabilidad objetiva según la opinión dominante.

Caso distinto sería, tercera hipótesis, el de quien se dedica habitualmente a realizar actividades, por ejemplo, de instalación o reparación, que por su propia naturaleza impliquen el deber de cuidado de conocer o verificar las características del producto que aplica. En esta hipótesis, entiendo que el prestador del servicio puede ser considerado responsable con los criterios de la Ley de productos defectuosos por el

16 PARra Lucán, M.A., «La responsabilidad civil por productos y servicios defectuosos. Responsabilidad civil del fabricante y de los profesionales» en Tratado de responsabilidad civil, coordinado por Reglero CAMPos, L.F., 2. a edición, Cizur Menor, Aranzadi, 2003, pág. 1347.

17 La responsabilidad civil del fabricante, Madrid, Civitas, 1990, pág. 67. 
concepto de «suministrador» a que se refiere el artículo 4.3, en las condiciones establecidas en esta norma; es decir, cuando en el plazo de tres meses no indique al perjudicado la identidad del fabricante o de quien le hubiera suministrado a él el producto.

Lo cierto, en relación con la Ley de productos defectuosos que nos ocupa, es que el hecho de que su ámbito se reduzca a los productos hace que, por ejemplo, no entren en su órbita los daños causados por una reparación defectuosa; piénsese en la de un vehículo. Pero los daños resultantes del carácter defectuoso de una pieza utilizada en la reparación sí podrían entrar en el radio de acción de la Ley, si se probase que el resultado fue sólo consecuencia del defecto del producto, no de la reparación. Otro ejemplo sería el del cosmético que se aplica y que causa daños a la cliente; debe distinguirse entre el posible carácter defectuoso del producto aplicado y la incorrección en el uso (intensidad, duración, lugar del cuerpo) de dicho producto. También puede pensarse en la hipótesis de un producto que se instala incorrectamente, siendo así que el producto como tal no es defectuoso: armario de cuarto de baño en cuya colocación se incurre por el instalador en la censurable práctica de no cubrir adecuadamente los contactos eléctricos; aunque en algún caso también podría decirse que es consecuencia del defecto del producto, que debe salir de la fábrica de forma que sea posible una adaptación directa a la red, sin ninguna manipulación (recordamos el caso resuelto por la sentencia de 26.1.90).

Es ejemplo de lo que decimos, así mismo, el de la medicina que se dispensa en un centro sanitario, dentro de un determinado régimen horario de administración de medicamentos; no hablo necesariamente de error del médico en la prescripción, sino de equivocación en la aplicación del fármaco, que como tal no tiene nada de defectuoso. Repárese también en los problemas que puede ocasionar el supuesto de venta de un producto y asistencia técnica posterior al comprador, sea en un solo acto, sea de forma intermitente (revisión de instalaciones de butano $)^{18}$.

En principio, parece que, estando por medio un producto, el daño que del mismo deriva, como fenómeno objetivo, debe considerarse que es «consecuencia» del producto; siendo de cargo del fabricante la prueba de que el perjuicio consistió en su defectuosa instalación o aplica-

18 VINEy, G., Débats, en Développements récents du droit de la responsabilité civile, Zurich, Schulthess Polygraphischer Verlag, 1991, pág. 328, pone de relieve la importancia que hoy tiene el deber del fabricante de vigilancia del producto después de su entrega, advirtiendo, sin embargo, que esta obligación no puede ser sancionada más que en el terreno de la responsabilidad por culpa. 
ción, si corrió a cargo de un tercero. Contra lo que opina MARKOVITS $^{19}$, entiendo que en este caso no debe jugar el criterio económico de los valores respectivos del trabajo y del objeto. La dificultad, en la práctica, será la de probar que el daño es consecuencia del defecto de la pieza y no del «servicio» consistente en colocarla o acoplarla al objeto reparado.

\section{Casuística de la jurisprudencia}

Los casos de daños producidos por servicios en sentido estricto, esto es, sin interferencia de un «producto» ${ }^{20}$, son variados. Citamos algunos extraídos de la jurisprudencia:

Los casos de defectuosa prestación por parte de agencias de viaje, como los que dieron lugar a las SSAP Alava 2.3.93 y Vizcaya 24.1.94; en ambos se trataba de frustraciones sufridas por viajeros en sus respectivos desplazamientos y en los dos la demanda fue estimada por las Audiencias respectivas.

En relación con otro tipo de servicios, puede citarse el caso del banco que paga un cheque falsificado, por no haber usado sus empleados la diligencia razonablemente exigible en el estudio del documento y en el descubrimiento de la falsedad. Esta reclamación fue resuelta por la sentencia de 1.3.94. Parecido fue el caso de la sentencia de 15.7.88, sobre transferencia bancaria incorrecta.

Otro pleito sobre servicios que producen daños: un calentador que cae al suelo al ser colocado y causa desperfectos; obsérvese que no se trata de defecto del calentador, sino de colocación defectuosa del mismo; esta reclamación fue resuelta por la SAP Burgos de 14.6.91.

También entrarían dentro de este grupo de casos otros muchos que llegan a los tribunales, aunque no habitualmente a las Audiencias y rara vez al Tribunal Supremo. Por ejemplo: daños sufridos por prendas en tintorerías y establecimientos de limpieza, daños producidos por la defectuosa reparación de automóviles, daños causados por la incorrecta aplicación de cosméticos y otros productos de belleza y daños producidos en el terreno de la asistencia sanitaria, haya o no utilización de ob-

19 Markovits, I., La Directive C.E.E. du 25 juillet 1985 sur la responsabilité du fait des produits défectueux, París, Librairie Générale de Droit et de Jurisprudence, 1990, págs. 176-177.

${ }^{20}$ Hablamos de «producto» en su acepción legal y que es, además, la natural. Porque no es posible desconocer la circunstancia curiosa de que en la terminología bancaria y de seguros se habla frecuentemente de «un producto», como puede ser una modalidad de inversión, una figura de seguro, etc. Parece claro que en este caso sufrimos la influencia terminológica del modo de hablar anglosajón. 
jetos en el sentido riguroso de la palabra; pongamos por caso, sueros, prótesis, etc.

Pero los ejemplos propuestos lo son, en su mayor parte, de «servicios» en sentido estricto, esto es, casos en que la actividad prepondera notoriamente sobre los bienes, objetos o productos. Donde reviste interés la cuestión que ahora planteamos es en las hipótesis en que esa primacía no es tan patente, sobre todo porque la actividad constitutiva del servicio aparece "más remota» para el consumidor que el objeto o producto causantes del daño.

El deslinde entre daños resultantes de un «producto» (a efectos de la LRCPD) y los acaecidos como consecuencia de indebida utilización de un producto (que en sí no es defectuoso) se aprecia con especial claridad en las numerosas sentencias en que el resultado lesivo tiene su origen (en el sentido físico) en productos pirotécnicos. Pero no procede incluir aquí estos supuestos, puesto que en ellos no existe de ordinario ninguna relación contractual «de servicios» entre el causante del perjuicio y la víctima (salvo el caso extremo de que esta última fuera la persona que contrató con la empresa pirotécnica la actividad propia del caso).

Casos en que se percibe la dificultad en la distinción entre productos y servicios son los constituidos por daños resultantes de la reparación de objetos; la fenomenología nos habla, sobre todo, de la reparación de vehículos de motor.

No pocas veces el daño deriva de un producto, en el sentido de que el resultado es, físicamente, consecuencia de la aplicación de una máquina, de una herramienta o de una pieza que son defectuosos; pero en circunstancias tales que el hecho de utilizar o acoplar unos u otros revela la «incorrección en el hacer» de quien lleva a cabo esas operaciones.

Sin perjuicio de que en algunas ocasiones pueda aplicarse la LRCPD (precisamente cuando entre el carácter defectuoso del producto y el daño pueda establecerse la adecuada relación de causalidad), no cabe duda de que en la mayor parte de las hipótesis procede la calificación de «servicio», por cuanto la incorrección está en el hacer de quien utiliza o manipula aquellos productos. Es un ejemplo de lo que decimos la SAP Córdoba 8.11.94, en que se ventilaba la posible responsabilidad de un taller de reparación de vehículos, en el que el demandante había dejado su automóvil para la colocación de bujías y circuito de refrigeración; al sacar el vehículo del taller y comenzar un viaje, se produjo el incendio de aquél, que ocasionó su total destrucción. Sin embargo, una vez superado el obstáculo de la prueba de la relación de causalidad, que la Audiencia salvó mediante el recurso a las presunciones, no hubo dificultad para la Sala en dictar sentencia estimatoria de la demanda, puesto que lo hizo en aplicación de la LCU, que como es sabido pro- 
yectó en su día su protección tanto para productos como para servicios defectuosos. Dice la sentencia que «la base sustantiva de la condena se encuentra no ya en el artículo 1.902 y siguientes del Código civil, sino más concretamente en la LCU, pues queda fuera de dudas que el actor tiene la condición de tal usuario y que la prestación del demandado consistió en un servicio a los que se refiere el artículo 1.2 de dicha Ley».

Semejante fue el caso de la SAP de Girona 4.6.93, en el que habiéndose dejado para reparación una embarcación en las instalaciones de la demandada (reparación consistente en parte en la sustitución del motor), al recogerla el propietario y salir a la mar se produjo una parada de ese motor; al intentar ponerlo en marcha el hijo de la actora, se produjo su explosión e incendio. La sentencia desestima el recurso de la demandada en aplicación de la LCU, deduciendo por vía de presunciones que la causa del incendio fue la deficiente reparación del motor.

También puede considerarse un caso «fronterizo» entre responsabilidad por servicios o por productos el de la sentencia de 24.6.91. Se reclamaba una indemnización por las lesiones sufridas por el actor al romperse la pata de apoyo de un remolque. La Sala entiende que la causa estuvo en el defectuoso diseño y soldadura de aquel elemento de sustentación con que el demandado había dotado a la máquina, construyéndolo con materiales en parte usados y con deficiente soldadura, determinante de que no formara un bloque sólido.

Otro grupo de sentencias en que se observa a veces una posible confusión entre servicio y producto es el constituido por daños acaecidos en el curso de una asistencia médica, o en general sanitaria.

El caso de la sentencia de 16.12.87 consistió en la reclamación entablada por los padres de una niña que sufrió la ceguera de ambos ojos como consecuencia de la aplicación de determinado suero en el postoperatorio de una intervención quirúrgica; en la Audiencia se había condenado al centro sanitario y al Insalud, así como al doctor en Farmacia que había preparado el suero en cuestión. El Tribunal Supremo declaró haber lugar al recurso del profesional, por estimar que el suero había salido de manos del mismo en buenas condiciones, siendo en el marco de su aplicación donde se produjo la precipitación causante del resultado. Interesa advertir que ésta es una de las primeras sentencias del Tribunal Supremo en que la condena de la institución sanitaria se funda en «ese conjunto de posibles deficiencias asistenciales» imputables al centro, aunque no quede probada la culpa de un concreto profesional.

En la sentencia de 5.5.88 se resolvió la reclamación formulada por los herederos de un enfermo que falleció por las deficientes condiciones del material clínico sanitario y, en especial, por la de los aparatos 
respiratorios empleados en los quirófanos. Habían sido demandados el cirujano, el anestesista, la supervisora e instrumentista de quirófano, el coordinador, ingeniero técnico encargado del mantenimiento, el representante legal de la sociedad que había reparado y revisado recientemente la mesa de anestesia y el Insalud. Condenado sólo este Instituto, el Tribunal Supremo declara no haber lugar a su recurso de casación. Se aprecia la existencia de culpa por su parte, consistente en haber consentido la utilización de aparatos sanitarios deteriorados por el uso y sin las suficientes garantías de buen funcionamiento «en materia tan delicada para la salud de las personas».

En la sentencia de 29.6.90 se trataba de la reclamación de los daños sufridos por la actora en el curso de una intervención quirúrgica. La paciente sufrió diversas lesiones como consecuencia del incendio de una lentina que protegía el sistema de anestesia cuando el médico practicaba un acto de microcirugía con utilización de rayos láser. El Tribunal Supremo declara que la condena de la Audiencia no hizo una rigurosa y absoluta aplicación de la responsabilidad objetiva o por riesgo, sino que la acordó como consecuencia de un «actuar no plenamente diligente en el autor de la intervención», razonamiento con el que salió al paso de la alegación del médico recurrente de haberse infringido la doctrina jurisprudencial que no presume la culpa del agente en casos de responsabilidad médica. Por otro lado, no se plantea el problema del posible carácter defectuoso de aparato emisor de los rayos, sino sólo el de la culpa por la actuación del profesional.

Hay un «producto», presumiblemente defectuoso a tenor de la LRCPD, en la sentencia de 22.2.91. En la realización de las operaciones de un tratamiento de endodoncia se rompió la lima que para ello utilizaba el odontólogo demandado (que lo había sido junto con la sociedad propietaria de la clínica en que trabajaba). La Sala maneja tres hipótesis, considerando que cualquiera de ellas conduce a la condena del médico demandado: de un lado, la circunstancia de que la lima estuviese deteriorada o en mal estado de conservación por el uso reiterado de la misma («fatiga de los materiales»), en segundo término un defectuoso manejo o incorrecta utilización del instrumento por parte del facultativo y, por fin, una insuficiente anestesia de la paciente, que no le impidió experimentar dolor y dar un golpe en el brazo al médico.

\section{Los casos especiales del gas y de la electricidad}

Si me ocupo de estos concretos productos-servicios, es porque precisamente en ellos se plantean los más significativos problemas en punto a la distinción, como paradoja, entre producto y servicio. 
Las referencias que a continuación se hacen a la Ley de productos defectuosos son sólo a efectos de determinar la frontera entre producto y servicio, en tanto en cuanto el primero, producto, se rige por dicha Ley, y en cambio el segundo, servicio, por la Ley de consumidores y usuarios.

a) El apartado 2 del artículo 2 de la LRCPD dice que «se consideran productos el gas y la electricidad». Estamos en presencia de otra «norma de definición», que puntualiza o advierte sobre el alcance del apartado 1 del mismo artículo La Directiva estableció en su artículo 2, último inciso, que "por "producto" se entiende también la electricidad». Nuestra Ley amplía la definición, incluyendo también — como producto a efectos de la misma- el gas. Se observará que la Ley va más allá de la Directiva, en las palabras, al hacer mención de la electricidad y también del gas. Es probable que la alusión a este último «producto» fuera innecesaria, teniendo en cuenta que la expresión «bien mueble», constitutiva de la definición general del apartado 1 de este artículo, quizá bastase para dar cabida al gas, puesto que se trata de un bien corporal, susceptible de presentarse en estado sólido o en estado gaseoso.

El hecho de que se trate de una fuente de energía no añade nada a esa noción general de «bien mueble», ni tenía por qué ser restricción o limitación de lo que por esta última expresión se entiende de ordinario. Del mismo modo, en la doctrina portuguesa CALVÃO DA SILVA ${ }^{21}$ señala que la expresa mención de la electricidad en la Directiva no era necesaria en el Derecho de su país, porque es pacífico que se trata de una cosa material o corpórea ${ }^{22}$. De igual modo que en la misma categoría de cosa material deben ser incluidas - añade - cualesquiera otras formas de energía que sean cosas aprehensibles o perceptibles por los sentidos, res quae tangi possunt; por ejemplo, el gas butano, el propano, el gas natural, el vapor, etc. ${ }^{23}$.

21 Responsabilidade civil do produtor, Coimbra, Almedina, 1990, págs. 608-609.

22 Legnani, A., (Prodotti difettosi. La responsabilità per danno, Rimini, Maggioli Editore, 1990, pág. 19) es del mismo criterio en lo que se refiere al Derecho italiano, advirtiendo que si la inclusión de la electricidad en la Directiva era una puntualización, la misma no era necesaria en aquel ordenamiento, a la luz del art. $814 \mathrm{CC}$ italiano. En la Consumer Protection Act 1987 británica (CPA) no se usa la expresión de «bienes muebles» o «muebles», sino la de «goods». Por eso, en ella se incluye específicamente la electricidad, para evitar cualquier duda sobre si es un «good» o un bien mueble.

23 En ORGALIME (Legal Affaire Commitee), Product Liability in Europe (A practical guide for industry), Bruselas, s. ed., 1993, pág. 11, se advierte que aunque no expresamente mencionados en la Directiva, el gas, el agua y otros (se trata de fuentes de energía) constituyen un «producto» en la medida en que son tangibles, por lo que entran en la categoría de «bienes muebles». 
De todas formas, el principal problema que plantean estos «productos» es el consistente en determinar cuándo se trata de daños efectivamente imputables a productos o, por el contrario, a servicios. A este extremo nos referiremos en cada uno de los dos casos.

b) Me refiero ahora al caso del gas.

Por lo que hace a este "producto», es necesario distinguir (diferencia que, sin embargo, es irrelevante a efectos de la LRCPD) entre daños causados propiamente por el gas y los debidos a defecto en los recipientes o conducciones del mismo.

No es fácil pensar en un caso de «gas defectuoso», en el sentido de que este objeto, sea en estado líquido, sea en el gaseoso, adolezca de alguna imperfección, aunque no cabe excluir la hipótesis de un gas que no se ajusta en su composición a las características que son las propias (o se tienen por tales) de ese producto, en cuanto destinado a un objetivo concreto; lo que desde luego es más verosímil (y así lo acredita la experiencia que deriva de los casos judiciales), es que el gas cause daño como consecuencia de roturas o averías de los sistemas de almacenamiento y transporte del mismo. En esta hipótesis parece que lo adecuado es hablar de responsabilidad de quien lleva a cabo aquel almacenamiento o aquel transporte, precisamente porque lo defectuoso es el elemento dedicado a efectuarlos. Sería el ejemplo de bombona averiada, o de tubo conductor agujereado, o de válvulas imperfectas. También es fácil de imaginar el caso en que un gas produce daño, pero no como consecuencia del mismo como producto, ni de los objetos utilizados en su almacenamiento o manipulación, sino por la actividad consistente en actuar con él; en definitiva, un caso de daños por «servicios», aunque esta expresión de «servicios» implique de ordinario la existencia de una relación contractual entre dañador y víctima.

Al igual que ocurre en el caso de la electricidad, la «experiencia» del gas como producto susceptible de causar daños por ser «defectuoso» (no por otros motivos, desde luego), es mínima. No cabe descartar en teoría que ese producto pueda ser, como tal, causante de daños subsumibles en el ámbito de nuestra Ley (por ejemplo, un gas que se suministra y cuyas características no corresponden a las que le son propias en un «estado» natural o normal de comercialización - por así decirlo-, de suerte que por ello un manipulador sufre una intoxicación), pero me parece que esa hipótesis es, a la vista de los casos de nuestra jurisprudencia, un tanto académica.

En efecto, debe advertirse que las sentencias de nuestro Tribunal Supremo en que el gas interviene como elemento del hecho dañoso se pueden encerrar fundamentalmente en dos grupos de casos: de un lado, 
aquellos en que el «accidente» no se produce como consecuencia del estado defectuoso del gas, sino a causa de defectos propios del recipiente o conducción en los que el gas se halla o por los que circula; en estas circunstancias, es muy probable que el acontecimiento lesivo pueda entrar en el radio de acción de la LRCPD, pero no por tratarse de un daño causado por el gas, sino por ser realmente consecuencia del mal estado de otro bien mueble.

Un segundo grupo de casos sería el constituido por aquellos en que no se trata tanto ni de que el gas sea «defectuoso», ni de que lo sea el recipiente o la conducción, sino en los que lo incorrecto o inadecuado es el «servicio» constituido por el suministro del gas al usuario. En relación con esta segunda hipótesis, por cierto, cabe decir que puede tratarse, en no pocos casos, de ejemplos de esa borrosa zona fronteriza que a veces existe entre «producto»y «servicio» ${ }^{24}$.

Pasamos ahora a examinar algunos casos de nuestra jurisprudencia:

La sentencia de 29.6.84 contempló un caso que acabó en condena de la empresa suministradora de gas.

La sentencia de 4.2.86 recayó en la demanda promovida por el empleado de una empresa contra ésta y dos empleados de la misma, demanda en la que el actor reclamaba la indemnización de los daños por él sufridos como consecuencia de la explosión de una máquina; la explosión se produjo porque los empleados había acoplado una botella de oxígeno en lugar de la que procedía, que tenía que ser de nitrógeno. La Audiencia condenó a los demandados al pago de una suma, recurriendo en casación el titular de la empresa; en el recurso se argumentaba que todo se había debido al error de la suministradora del gas, que había entregado oxígeno en lugar de nitrógeno. El Tribunal Supremo dice que esta circunstancia, junto con otras que contempla, «no desvanecen la

24 Téngase presente que en la CPA se mencionan explícitamente, como «producto», el gas y el agua. Y además, con la importante advertencia de que en ella se establece $(s 46,1)$ que con esos términos se incluye la dispensación del servicio por cuya virtud se pueden obtener gas o agua para su uso. Esta particularidad de la Ley británica podría hacer pensar que cabe la misma extensión en el caso de la Directiva y, por ello, en el de la Ley española. En efecto, dado que el supuesto de «gas defectuoso» (dígase lo mismo de la electricidad) será una verdadera rareza, movería a pensar que entran en el ámbito de nuestra Ley los casos en que el daño sea consecuencia de cualquier acontecimiento derivado del suministro de gas (o de electricidad); por ejemplo, cuando las instalaciones, propiedad del suministrador o sometidas a su control, adolecen de defectos o irregularidades que dan lugar a fugas. No me refiero a defectos del producto derivados de su fabricación (porque en este caso habría que decir que el sometido a la LRCPD es ese fabricante), sino a deficiencias en la conservación o incorrecciones en su utilización. No obstante, esta posible interpretación colisiona con el hecho de que en los casos de que hablo hay una innegable preponderancia del aspecto «servicio» frente al «producto» constituido por el gas o la electricidad. 
negligencia de los empleados de la factoría, no vigilando la utilización de un producto en vez de otro». Cabe suponer que si la demanda se hubiera planteado también contra dicho suministrador, probablemente habría sido también condenado, de ser ciertas las aseveraciones del recurrente. En todo caso, es claro que no se trata de un caso de gas «defectuoso», sino de confusión entre un gas y otro.

En la sentencia de 8.11.86 se absolvió a Butano, S.A., que había sido demandada junto con otros, porque la explosión y ulterior incendio producidos en la casa de los demandantes se había producido después de que estos últimos trasladaran la dependencia de cocina a un lugar distinto del originario, sin que fuera revisada la nueva instalación por los organismos y entidades (entre ellos Butano, S.A.) que habían verificado la primitiva instalación. Por tanto, la Sala consideró que no había mediado culpa de los empleados de dicha empresa. El Tribunal Supremo argumenta que «no se está ante un supuesto en que por falta de elementos probatorios deba juzgar la presunción de culpabilidad, sino ante un caso en el que la valoración del abundante material probatorio ha llevado a los juzgadores de instancia a excluir la concurrencia del elemento subjetivo de la responsabilidad, es decir, a eliminar el requisito de la culpa».

La de 24.6.88 trató también sobre un caso de explosión de gas, pero en este caso gas metano en una mina.

Un caso de daños por incendio, consecuencia éste a su vez del mal estado de una bombona de gas, fue el resuelto por la sentencia de 26.12.88. Se produjo el incendio en la fábrica de la codemandante (la otra actora fue su compañía de seguros), entablándose la demanda contra «Butano, S.A.», contra los titulares de la empresa distribuidora del propano y contra dos empleados de esta última. La Audiencia absolvió a uno de estos empleados y condenó a los demás demandados. Interpuesto recurso de casación por Butano, S.A., el Tribunal Supremo declaró no haber lugar al mismo ${ }^{25}$.

La sentencia de 21.4.89 conoció de la reclamación formulada contra Butano, S.A., entre otros, como consecuencia de los daños sufridos

25 La Sala desmonta la argumentación de la recurrente encaminada a obtener su exculpación, a cuyo efecto la sentencia recuerda la jurisprudencia consolidada en punto a culpa «in eligendo» o «in vigilando» que se proyecta sobre Butano, S.A. respecto de sus distribuidores, «máxime tratándose de mercancía sumamente peligrosa y con envases de producción y mantenimiento propio y exclusivo que debe inspeccionar en sus depósitos al ser rellenados», culpa de la que «solamente podría eximirse probando que había extremado esa diligencia en tales términos que no hubiera más conclusión, por exclusión, que la producción del daño se haya debido a caso fortuito o fuerza mayor». Todo ello, en vista «de la finalidad de la protección de terceros en los irremediables avances tecnológicos de las actividades humanas que llevan aparejados tangibles peligros y riesgos». 
por un edificio a causa de una explosión de gas. Estimada parcialmente la demanda por la Audiencia, el Tribunal Supremo declara no haber lugar al recurso de casación interpuesto por Butano, S.A. La Sala desestima, entre otros, el argumento invocado por la recurrente de que en la zona de instalación del servicio no existían orificios de escape de gas; se razona por la sentencia que también aquí gravitaba sobre la recurrente la responsabilidad de lo ocurrido, puesto que su inspección no hizo notar la peligrosa inexistencia de dichos orificios.

En la sentencia de 7.6.89 se resolvió la reclamación formulada por los padres del empleado de una empresa de fontanería que a su vez trabajaba en las instalaciones de B.E., S.A. El trabajador falleció cuando al percibir señales de un escape de gas, descendió solo y sin protección alguna a un lugar de la factoría al que B.E., S.A. tenía prohibido entrar. Se produjo asfixia del trabajador, resultante de la fuga de gas nitrógeno que a su vez tenía su causa en la rotura de una conducción subterránea. El Juzgado y la Audiencia habían desestimado la demanda y el Tribunal Supremo declaró no haber lugar a recurso de casación de los actores.

La de 13.6.89 conoció del caso consistente en el fallecimiento de la madre de los actores y en gravísimas lesiones de su padre. Ambos efectos habían sido consecuencia de inhalaciones de un gas (bromuro de metilo) procedente de un escape de un extintor de incendios. La Audiencia había condenado a la Compañía Telefónica Nacional de España (uno de los demandados) y el Tribunal Supremo declaró no haber lugar a su recurso. La Sala parte de la conducta culposa de Telefónica, a la que corresponde la responsabilidad de las consecuencias que puedan derivar de la instalación y conservación de aparatos extintores de su propiedad, con invocación de la doctrina de la inversión de la carga de la prueba, así como de la de la creación del riesgo. Se excluye la aplicabilidad del artículo 1.105 del Código civil (presunta apertura de la válvula de seguridad por una persona ajena a la Compañía), como «hecho nuevo». Se observará que tampoco aquí es el gas, en rigor, la causa del daño (desde luego en sentido jurídico), sino que lo fue el presumible mal estado del extintor como envase de aquel producto.

La sentencia de 2.3.90 se dictó en la demanda promovida en reclamación de los daños producidos como consecuencia de un incendio. Se había demandado a una empresa que parece ser que fue la suministradora de la bombona, a Butano, S.A. y a una compañía aseguradora. Estimada parcialmente la demanda por la Audiencia, que condenó solidariamente a las dos primeras demandadas y a la tercera hasta el límite de la cobertura del seguro, el Tribunal Supremo declaró no haber lugar a recurso. 
Hay muchas sentencias posteriores, sobre casos similares, pero prácticamente todas siguen los mismos criterios.

c) Me refiero ahora a la electricidad.

(i) MARKOVITS ${ }^{26}$ dice que si la Directiva hizo expresa mención de la electricidad fue, sin duda, porque este «producto» no es considerado como un bien, sino como una energía, en ciertos ordenamientos ${ }^{27}$.

Es claro que no entra en esta previsión normativa el supuesto de daños causados por objetos que funcionan con energía eléctrica, dado que los mismos encontrarían cobijo en el genérico concepto de «bien mueble» (o en su caso bien mueble incorporado a un inmueble) del apartado 1 del artículo $2^{28}$.

Se ha advertido, con razón, que los «casos de electricidad defectuosa» no serán muy frecuentes ${ }^{29}$. Más bien habría que pensar en supuestos en los que los perjuicios o lesiones sean debidos a defectos en la transformación o distribución de electricidad; difícilmente podrá hablarse de defecto en la producción de esta energía. Esta consideración pone de relieve la obligada distinción entre productores de energía eléctrica y distribuidores de la misma. Cuando no concurren en una misma empresa ambas condiciones o cualidades, parece que debe entenderse que el «producto» consistente en electricidad es «fabricado», a efectos de LRCPD, por el empresario distribuidor, que es el que aproxima o hace llegar tal producto al consumidor o cliente. Si bien tampoco

${ }^{26}$ La Directive C.E.E. du 25 juillet 1985 sur la responsabilité du fait des produits défectueux, París, Librairie Générale de Droit et de Jurisprudence, 1990, págs. 163-164.

${ }^{27}$ Una vez promulgada la Ley española, ya no tiene sentido la advertencia que en su día hacía Bercovitz, R., con toda razón (La responsabilidad de los fabricantes en la Directiva de las Comunidades Europeas de 25 de julio de 1985, en Estudios jurídicos sobre la protección de los consumidores, BerCovitz, A. y BerCovitz, R., Madrid, Tecnos, 1987, pág. 273), en el sentido de que la mención de la electricidad en el artículo 2 de la Directiva no permitía extender la regla a otros suministros, entre los que citaba el gas; la inclusión de este último «producto» por parte de nuestra Ley resuelve el problema. Por otro lado, hay que señalar que la inclusión de la electricidad entre los «productos» de la Directiva ha suscitado opiniones contrarias. Por ejemplo, CAmpbell, D. y C., International Product Liability, Londres, Lloyd's of London Press Ltd., 1993, pág. 14, n. 90, opinan que en relación con la electricidad se plantea el particular problema acerca del momento en que se ha puesto en circulación, ya que de ordinario no es claro; la electricidad circula a través de líneas, no se entrega por un fabricante a un vendedor y por un vendedor a un cliente como cualquier otra mercancía; la inclusión de la electricidad oscurece la definición de «materialidad» y, por otra parte, los autores de la Directiva habrían hecho mejor no incluyéndola.

${ }^{28}$ Legnani, op. cit., pág. 19; CARnevali, M., Comentario al artículo 2 de la Ley italiana de transposición, en La responsabilità per danno da prodotti difettosi (G. ALPA y otros), Milán, Giuffrè, 1990, pág. 11.

29 Orgalime, Product ..., pág. 11. 
cabe descartar, visto el «ámbito de protección» que establece el artículo 10, que la víctima del daño sea el distribuidor como consecuencia de actuaciones del productor de la energía, aunque parece que será un caso más $\operatorname{raro}^{30}$.

Pero la gran cuestión que suscita esta norma es de nuevo la de distinguir entre producto y servicio, porque en la inmensa mayor parte de los casos, de los daños en que «interviene» la energía eléctrica, esos daños no son sino expresión del peligro que lleva consigo la electricidad, pero como consecuencia de sus conducciones, sus enlaces, su utilización para hacer funcionar determinados objetos, etc. ${ }^{31}$ Podría pensarse, en principio, que la norma que nos ocupa da cabida a todos aquellos casos, no infrecuentes en nuestra jurisprudencia, en que una persona sufre lesiones físicas como consecuencia del contacto con un tendido o red de distribución de energía eléctrica. Pero en hipótesis como éstas quizá quepa decir que el daño no es tanto producto de la electricidad misma (aunque sea la causante del perjuicio), cuanto de la instalación por la que discurre, defectuosamente proyectada o ejecutada. Ahora bien, lo cierto es que la consecuencia perjudicial no deriva precisamente de la electricidad, sino de que las condiciones de instalación o utilización de la misma son tales que someten al riesgo de contacto con esta energía (por ejemplo, redes a baja altura, columnas de excesivamente fácil acceso, etc.). Por ello, entiendo que aunque se produjese un daño «por efecto de la electricidad», pero siendo su causa una deficiencia en las instalaciones del suministro, aunque esa deficiencia fuese imputable al propio productor o distribuidor de la energía, existe un ingrediente de prestación de hacer tan importante que prevalece sobre el «producto»; de suerte que no parece justificada la aplicación de un régimen de responsabilidad objetiva.

De otro lado, creo que la responsabilidad objetiva del fabricante o del distribuidor de electricidad debe ser excluida en aplicación del argumento de que en estas hipótesis no «se pone en circulación» ningún producto. La «puesta en circulación», o mejor dicho el suministro, de la electricidad (respecto al usuario) es el paso de la energía a través del

30 Reglero, L.F., Una aproximación a la Ley 22/1994, de 6 de julio, de responsabilidad civil por los daños causados por productos defectuosos, «Iniuria», núm. 3, julio-setiembre 1994, pág. 51, después de haber advertido que si bien el gas es un bien corporal susceptible de ser defectuoso, dice que lo normal es que los daños procedan de los sistemas de suministro, almacenamiento, etc.; y añade que en cuanto a la electricidad el defecto no residirá en el producto en sí, cuanto en esos sistemas por él citados.

31 Sobre las dificultades que entraña la distinción entre producto y servicio, referidas a la electricidad en concreto, se expresó PARRA LuCÁn, M.A., Daños por productos y protección del consumidor, Barcelona, José María Bosch Editor, 1990, págs. 484-487. 
contador, no cualquier otra vicisitud que ulteriormente pueda suceder como consecuencia del uso de la energía eléctrica.

Por tanto, los casos de aplicación de esta regla son aquellos en que cualquier modificación del régimen normal de suministro de la energía eléctrica cause daños. Cabe pensar en hipótesis en que el aumento de la «potencia» de la electricidad daña un aparato que funciona con dicha energía ${ }^{32}$, si bien ha de tratarse (para que entren dentro del ámbito de esta Ley) de cosas objetivamente destinadas al uso o consumo privados y en tal concepto hayan sido utilizadas principalmente por el perjudicado (artículo 10.1). Más difícil, aunque no imposible, es el caso de daños corporales derivados de ese aumento de potencia del suministro ${ }^{33}$.

Otra hipótesis sería la de interrupción o corte del suministro de energía. Por ejemplo, por esa causa se paraliza el sistema refrigerador de un almacén y se pierden las mercancías depositadas en él. Caso similar sería el de corte del suministro que acarrea la interrupción de una intervención quirúrgica en un hospital, con daños al paciente. Este último supuesto obliga a introducir en la reflexión un elemento distinto, como es el de la obligación del centro sanitario de contar con un generador, previsto precisamente para estas hipótesis; si no existiera, cabría hablar de culpa o simple intervención de un tercero, circunstancia que no exime de responsabilidad al fabricante, según establece el artículo 8.

LEGNANI ${ }^{34}$ opina que se crearían delicados problemas de no fácil solución en el caso de responsabilidad exclusiva o concurrente de un tercero o de culpa exclusiva (o concurrencia de su culpa) por parte de la propia víctima. Lo hace refiriéndose a precisamente al caso en que por parte de un usuario (por ejemplo, un hospital o el propietario de una instalación de ascensores) no se hubiesen utilizado los aparatos o mecanismos de seguridad exigibles o razonables para la hipótesis de una caída o interrupción de tensión. Por el contrario, CALVÃO DA SILVA $^{35}$ entiende que el nuevo régimen de responsabilidad no se aplica al caso de no suministro o interrupción del suministro de electricidad,

32 Ejemplo propuesto por CARnEvali, op. cit., pág. 11.

33 VALSECCHI, Commentario d. P.R. 24 maggio 1988, n. 224, sulla disciplina del danno causato da prodotti difettosi, en Responsabilità del produttore e nuove forme di tutela del consumatore (a cargo de DrAETTA y VACCÀ), Milán, EGEA, 1993, pág. 146, recogiendo el criterio de la doctrina italiana, estima que la norma debe entenderse exclusivamente referida a aquellos casos en que el «producto-electricidad» no posee todas las características de voltaje, amperaje, etc., que son normalmente tenidas en cuenta o comprometidas por la empresa suministradora.

${ }_{34}$ Op. cit., pág. 21.

35 Op. cit., pág. 611, n. 3. 
porque en esta hipótesis no se puede hablar de producto defectuoso. Es una visión razonable, aunque pone de relieve una cierta incongruencia al aplicar un régimen más riguroso al caso de bajada o disminución de la tensión del suministro que al de interrupción total del mismo.

No obstante, insisto, en los casos de daños causados por la electricidad se plantea de nuevo la cuestión de si el daño es consecuencia de un producto defectuoso o, más bien, de un servicio defectuoso. Me inclino por esta segunda solución, puesto que lo que por el suministrador se compromete (y la otra parte espera) no es tanto una aportación de la energía como bien, sino la dotación de un servicio en el que las prestaciones de hacer superan a las de «dar» en la natural valoración de las cosas según la experiencia común.

\section{La acumulación de acciones, como posible fórmula procesal}

La dificultad en el deslinde entre producto y servicio no es una simple cuestión académica, sino que puede originar dificultades en el aspecto procesal. Me refiero en concreto a la formulación, por parte del demandante, de la fundamentación jurídica de su demanda.

$\mathrm{Si}$, como puede ocurrir en ocasiones, el perjudicado opta por dirigir su reclamación contra quien le prestó el servicio causante del daño, pero siendo posible que este último fuera consecuencia no del servicio como tal, sino del defecto del producto utilizado o aplicado por aquél, y con independencia de que la responsabilidad del prestador del servicio pueda venir impuesta con la sola invocación de la LCU, creo que es aconsejable la formulación alternativa de la pretensión, es decir, alegar como fundamentación jurídica de la misma tanto la propia LCU como el artículo 1 de la LRCPD. Si, en la hipótesis que planteo, el perjudicado utiliza alternativamente la doble fundamentación jurídica que nos ocupa, con íntegra descripción de los hechos y de su resultado (entendiendo como tal una narración que tenga cabida en cualquiera de esas dos fundamentaciones), el órgano judicial deberá acoger la que estime pertinente y — cumplidos los demás requisitos- dictar sentencia condenatoria.

El fundamento sería el artículo 72 de la Ley de Enjuiciamiento civil. Sin perjuicio de las dudas que pudiera haber sobre el concepto de «causa de pedir» que utiliza ese precepto, parece evidente que «el título» es el mismo, puesto que se trata del daño sufrido por el perjudicado demandante. Sin que en este caso, a mi entender, entre en juego, a efectos de «título», la circunstancia de que se trate de una relación contractual o extracontractual respecto a uno u otro demandados, ya que en este caso la distinción entre responsabilidad contractual y extracontrac- 
tual (por utilizar los términos clásicos) carece de sentido, tanto a la luz de la LCU como de la LRCPD ${ }^{36}$.

Otra posibilidad es la de que, considerando el demandante que puede existir responsabilidad del prestador de servicios y también del fabricante del producto por él aplicado o utilizado, le interese entablar la reclamación contra ambos - cosa que en determinadas ocasiones puede ser muy razonable, siempre con el inconveniente de la posible desestimación de la demanda respecto a uno de ellos, con lo que eso comporta en punto a costas-, en cuyo caso entiendo que es perfectamente viable la demanda contra uno y otro; en el caso del prestador de servicios, al amparo de la LCU, y en el del fabricante con fundamento en la LRCPD. Entiendo que esa acumulación de acciones es posible al amparo del artículo 71.2 de la Ley de Enjuiciamiento civil. No veo que en este caso exista la incompatibilidad a la que se refiere ese apartado 2, pero en todo caso el actor podría hacer uso de la fórmula que permite el apartado 4 del mismo artículo 71, esto es, la de expresar la acción principal y la otra u otras que ejercita para el solo evento de que la principal no se estime fundada.

\section{Responsabilidad del suministrador de servicios}

\section{Consideraciones generales}

El régimen de responsabilidad por daños causados por servicios es doble en nuestro ordenamiento ${ }^{37}$.

Por un lado, es de aplicación el sistema general de responsabilidad del Código civil. Esto es, el propio de la contractual (artículos 1.101 y concordantes) y el de la extracontractual (artículo 1.902 y sus también concordantes $\left.^{38}\right)$.

36 En efecto, de las dos leyes españolas a que nos referimos en el texto puede afirmarse con verdad que la distinción entre responsabilidad contractual y extracontractual, en otro tiempo clara, se ha ido haciendo cada día más difusa. Así lo dice en la doctrina italiana SARAVALLE, A., Responsabilità del produttore e diritto internazionale privato, Padua, CEDAM, 1991, págs. 54 ss.

37 No está de más recordar que en esta materia, a diferencia de lo que ocurre con el suministrador de productos, no existe ninguna regulación comunitaria de carácter general. Fracasó — según se dice como consecuencia de la presión de algún lobby profesional— la propuesta de Directiva sobre responsabilidad del prestador de servicios. En el párrafo primero del artículo 1 del proyecto, se definía como servicio «cualquier prestación realizada a título profesional o de servicio público, de forma independiente, a título oneroso o no, que no tenga por objeto directo y exclusivo la producción de bienes o la transferencia de derechos reales o de propiedad intelectual».

38 Entre estos últimos, según la jurisprudencia, también los artículos 1.103 a 1.107, a pesar de su emplazamiento sistemático en sede de responsabilidad contractual. 
De otra parte, el régimen especial de la Ley de consumidores y usuarios.

Podría pensarse que, a su vez, existen otros regímenes, por así decirlo, más especiales, como los que formulan reglas de «responsabilidad» en relación con determinadas actividades concretas, calificables como de servicios. Pero dudo de que en esos casos estemos en presencia de un auténtico régimen de responsabilidad distinto del general del Código civil o del verdaderamente especial de la Ley de consumidores y usuarios.

Voy a proponer dos ejemplos muy recientes.

La Ley de 12 de julio de 2002 sobre servicios de la sociedad de la información y de comercio electrónico contiene, en sus artículos 13 a 17, un denominado régimen de responsabilidad. Así se rubrica la sección de la que dichos artículos forman parte.

En los sucesivos preceptos se alude a la responsabilidad de los prestadores de los servicios de la sociedad de la información (13), de los operadores de redes y proveedores de acceso (14), de los prestadores de servicios que realizan copia temporal de los datos solicitados por los usuarios (15), de los prestadores de servicios de alojamiento o almacenamiento de datos (16) y de los prestadores de servicios que faciliten enlaces a contenidos o instrumentos de búsqueda (17).

En la Ley de 20 de diciembre de 2003, de normas reguladoras de firma electrónica, el artículo 22 versa sobre «responsabilidad de los prestadores de servicios de certificación» y el 23 sobre limitaciones de responsabilidad de dichos prestadores de servicios. Todo ello, en un capítulo rubricado con la palabra «responsabilidad».

Los ejemplos que acabo de proponer no son, a mi juicio, en modo alguno, constitutivos de verdaderos regímenes de responsabilidad. Para que pueda hablarse de esto último, es necesario, a mi entender, que una determinada regulación legal establezca, respecto al régimen general naturalmente aplicable, o bien un criterio de imputación específico, o bien una definición, igualmente específica, del daño resarcible.

Lo que en los citados preceptos se contiene no es sino un conjunto de reglas encaminadas a concretar o precisar reglas de actuación de los profesionales a los que los propios preceptos se refieren, esto es, los de los servicios de la sociedad de la información y los de los prestadores de servicios de certificación en la firma electrónica.

Bien podría decirse, a mi entender, que esas mal llamadas reglas de responsabilidad no son sino una especie de «codificación» de la lex artis propia de los respectivos profesionales o prestadores de servicios. Lo que significa que dichas reglas no constituyen más que una tipificación de conductas susceptibles de utilizarse en el momento y a efectos 
de determinar cuándo se ha incurrido en culpa, bien sea la propia de la responsabilidad contractual (artículo 1.101), bien la de la extracontractual (artículo 1.902).

Lo mismo puede decirse, según creo, de otras reglas de responsabilidad presentes en regulaciones de otros ámbitos de prestación de servicios. Por ejemplo, los de transportes, servicios financieros, auditoría, etc. ${ }^{39}$.

Es excepción de lo que acabo de decir, y por eso un auténtico régimen especial, el del transporte aéreo, por cuanto la Ley de navegación aérea de 21 de julio de 1960 introdujo en nuestro ordenamiento un sistema de responsabilidad distinto del común del Código civil. No es necesario recordar el régimen de responsabilidad objetiva instaurado por sus artículos 119 y siguientes; en esto radicó la especialidad de la citada Ley: en instalar un criterio de atribución de responsabilidad distinto del general del Código, de carácter netamente culpabilista.

\section{El régimen de responsabilidad del Código civil}

Sentado, pues, que la responsabilidad del suministrador de servicios se somete al régimen general del Código civil y al especial de la Ley de consumidores y usuarios, corresponde examinar a grandes rasgos el alcance de uno y de otro.

a) Por lo que respecta al sistema de responsabilidad con sede en el Código civil, puede considerarse, en primer lugar (al menos así lo creo), que la palabra «servicios» debe entenderse en el sentido más amplio, que le hace equivaler a «actividad». Dicho en términos más conceptuales, cualquier obligación de las de hacer, no sólo las subsumibles en la categoría del llamado por nuestro Código civil arrendamiento de servicios. También tiene cabida, a mi juicio, a estos efectos, el tipo contractual que el Código llama arrendamiento de obra. El que en este último caso el obligado comprometa un resultado (el opus consumatum et perfectum del que habla el Derecho romano) no impide advertir que ese

39 En todo caso, y aunque casi no sea necesario decirlo, debe tenerse en cuenta que estos supuestos regímenes sectoriales de responsabilidad (que no lo son) para determinados servicios deben distinguirse con precisión de las disposiciones legales sobre infracciones y sanciones en determinados ámbitos de actividad. Esas disposiciones sólo son una disciplina administrativa, circunscrita por tanto al campo de actuación de la actividad de policía de la Administración. Es digno de señalarse el rigor con el que en este punto se expresa el artículo 93.1 de la Ley de seguridad aérea de 7 de julio de 2003. En el se dice que «la responsabilidad por las infracciones tipificadas en esta Ley es de naturaleza administrativa y no excluye las de otro orden a que hubiere lugar». Similar es el caso de la Ley de auditoría. Pero son incontables los ejemplos: banca, seguros, transportes, servicios financieros, etc. 
obligado (el contratista, en denominación genérica aunque no muy adecuada para todas las hipótesis) queda sujeto a un deber de prestación de hacer, perfectamente subsumible —en relación con lo que ahora nos ocupa- en la noción, más económica que jurídica, de «servicios».

La única salvedad que debe de hacerse, en el marco de la presente ponencia, es la de que, dado que en ella se habla del «suministrador», el prestador de servicios del que hablamos ahora es el que los desarrolla de forma habitual o profesional, esto es, no de manera ocasional y aislada.

Esta última puntualización, no obstante, no ha de ser demasiado significativa en el terreno de las soluciones. Ahora bien, que no sea significativa no quiere decir que sea de todo punto irrelevante. Por ejemplo, se me ocurre que la prestación de servicios (en el sentido más amplio de la expresión), cuando se desarrolla de forma habitual o empresarial, puede tener consecuencias jurídicas, y quizá no pequeñas a veces. Por ejemplo, en relación con: (i) toma en consideración (o no) de la lex artis; si con esta expresión damos nombre a un canon de conducta o pauta de actuación propios de una actividad profesional, sólo parece que deba ser utilizada cuando, en efecto, el prestador de servicios los desarrolla de manera habitual y para indiscriminados clientes; y en segundo lugar, (ii), a efectos de la eventual utilización del criterio de integración de contrato constituido por el «uso» a que se refiere el artículo 1.258 del Código civil; en efecto, parece que el uso entraña la contemplación del modo natural o normal de proceder en un sector profesionalizado de «servicios».

b) Normalmente, la responsabilidad del prestador de servicios, bajo el régimen del Código civil, será la de carácter contractual, por existir entre el prestador y el perjudicado una relación de ese tipo, de ordinario subsumible en las categorías legales del arrendamiento de servicios y del arrendamiento de obra. No parece tan claro que pueda serlo en la figura del mandato. Sí, en cambio, en la de la mediación.

Sin embargo, téngase presente lo que al comienzo decía sobre la doctrina jurisprudencial que reduce el régimen de la responsabilidad contractual al supuesto en el que el hecho dañoso acontezca dentro de la rigurosa órbita de lo pactado y como preciso desarrollo del contenido negocial, pues si se trata de negligencia extraña a lo que constituye propiamente materia del contrato, desplegará sus efectos propios la responsabilidad aquiliana.

Esta orientación jurisprudencial, en principio no tan extraña como pudiera parecer, puede a veces conducir a soluciones no demasiado felices. Y cuando hablo de soluciones, no me refiero tanto al desenlace 
de un pleito en términos de lo que vagamente llamamos «justicia material», sino a argumentos jurídicos en sentido estricto, esto es, técnicos o dogmáticos.

Me permito reproducir aquí lo que hace muchos años escribí sobre la sentencia de 10 de junio de 1991.

El demandante, como consecuencia de la caída de un cable de arrastre en un telesquí, sufrió graves daños. Repárese en que se trata de un caso que casi coincide con otro de la jurisprudencia italiana, muy mencionado por la doctrina de aquel país.

La sociedad propietaria de la explotación tenía concertada una póliza que se denominaba «de seguro de responsabilidad civil general»; garantizaba «el pago de las indemnizaciones pecuniarias que, con arreglo a los artículos 1.902 y siguientes del Código civil, se viera obligada a satisfacer la entidad contratante por la responsabilidad civil extracontractual que pudiera serle imputada por los daños directos ocasionados a terceros, en sus personas o bienes, con motivo de la explotación y propiedad de las instalaciones» que al efecto se describían en el propio contrato. Repárese en que los términos de la póliza, que hemos transcrito literalmente, circunscribían su cobertura, de forma particularmente precisa, al ámbito de la responsabilidad extracontractual.

Demandadas la sociedad propietaria de las instalaciones y la aseguradora, el Juzgado de Primera Instancia estimó parcialmente la demanda y condenó solidariamente a las dos demandadas. La Audiencia estimó la apelación de la compañía de seguros, a la que absolvió.

El Tribunal Supremo desestimó el recurso de casación de la empresa titular de la explotación pero en cambio declaró haber lugar al del demandante, confirmando en definitiva la sentencia del Juzgado.

Se observa en el razonamiento de la Sala el objetivo de llegar a una calificación (responsabilidad extracontractual) que permitiera condenar también a la compañía aseguradora demandada. Y para ello el Tribunal hace, a mi juicio, una prestidigitación dialéctica notable. Partiendo de lo que viene siendo doctrina jurisprudencial al respecto - la que antes he citado- dice el Supremo que la culpa imputada en el caso no nace de un defectuoso cumplimiento por parte de la propietaria de las instalaciones de esquí de las obligaciones originadas en el contrato de transporte concertado con el perjudicado, sino que se trata de un accidente sobrevenido por un funcionamiento defectuoso de las instalaciones, que motivó el descarrilamiento del cable y su caída por falta de las medidas de seguridad adecuadas para evitar daños a los usuarios de ese medio de transporte. Concluyendo el Tribunal que de todo lo anterior se desprende, no obstante la existencia de una relación contractual, que el hecho causante del daño no puede incardinarse como producido den- 
tro de la órbita de esa relación y como desarrollo de su contenido negocial; en consecuencia, entra en juego el artículo 1.902, definidor de la responsabilidad extracontractual.

No me parece muy defendible la tesis de que proporcionar seguridad al cliente en el transporte no sea una de las obligaciones naturales del contrato de este nombre. Dicho de otro modo, el porteador se obliga a transportar y a hacerlo bien, esto es, de suerte que el viajero no sufra daños como consecuencia de defectos del propio sistema de transporte.

Por eso, creo que es más defendible el razonamiento de la sentencia de 6 de noviembre de 2003.

La demandante había ejercitado acción de responsabilidad contractual, derivada del contrato de transporte de viajeros, contra dos entidades ferroviarias, por razón de un suceso consistente en que la demandante, que a la sazón era menor de edad, al tratar de acceder al vagón de un tren, cuando éste ya había iniciado su marcha y cerrado sus puertas, intentó cogerse a una barra de sujeción. La actora cayó y fue arrollada por el convoy, sufriendo graves heridas y secuelas.

Con independencia del problema de si la demandante había adquirido o no un billete para el viaje, extremo ahora irrelevante, la sentencia dice:

«Por otra parte, tampoco es aceptable el argumento de la primera instancia de que el luctuoso suceso cayó fuera de la órbita del contrato de transporte. No es así; en la consumación de éste, en el momento en que la viajera la comenzaba se produjo el hecho; el transporte, que comienza con la puesta a disposición del viajero del medio para producirlo, comprende el hecho del inicio o del intento del mismo, que no llegó a producirse precisamente por un hecho dañoso.

En consecuencia, la posible responsabilidad deriva del cumplimiento del contrato de transporte, se trata de responsabilidad contractual, no de la extracontractual que es más bien una obligación de reparar el daño por quien lo ha producido por un acto ilícito, sin mediar una relación obligacional previa. Cuya responsabilidad contractual no está sometida al breve plazo de prescripción anual sino al de quince años, de las acciones personales que no tienen plazo especial de prescripción. En este sentido se estima el recurso.»

La sentencia, por cierto, consideró que había existido cumplimiento defectuoso del contrato de transporte, como culpa de la compañía ferroviaria. Dice al respecto la resolución:

«El motivo debe ser estimado. No se considera la negligencia en el cumplimiento de la obligación de la entidad ferroviaria, como sujeto del contrato de transporte, consistente en una acción culposa de los 
empleados o dependientes, sino en una omisión. Tal como se destaca desde la demanda, la omisión consistió en no prever mecanismos que impidan que un viajero abra las puertas de un vagón cuando el tren ya ha emprendido la marcha; el razonamiento que hacen las demandadas de que en aquella fecha -1981-la técnica no permitía tal mecanismo, carece de toda prueba; es decir, las partes demandadas, pese al reconocimiento de tal omisión, no han probado, ni intentado siquiera, que en aquella fecha no era negligente. La parte actora ha probado tal negligencia - el abrir la puerta con el convoy en marcha-y la demandada no ha probado que la misma no tiene nexo causal -la técnica no permitía otra cosa en aquel tiempo-con la entidad ferroviaria.»

c) Pero tampoco cabe descartar, aunque será menos frecuente, que la responsabilidad del suministrador de servicios pueda revestir carácter de extracontractual.

Puede ser ejemplo la hipótesis del auditor de cuentas, en auditorías voluntarias para cierto tipo de operaciones especificadas (pongamos por caso, una auditoría de compra), cuando un tercero o categoría de terceros —no cualquiera, desde luego- confió en el informe negligentemente elaborado por el profesional ${ }^{40}$.

Lo que ocurre es que en esta segunda hipótesis, la de responsabilidad extracontractual, casi pierde todo su significado el hecho de que el responsable sea un suministrador de servicios. La propia circunstancia de que entre el dañador y el perjudicado no exista vínculo contractual priva de toda particularidad al hecho de que haya habido en aquél, el dañador, un comportamiento calificable como servicio en el plano económico. El juicio de responsabilidad girará en torno a los criterios y principios del régimen común de responsabilidad civil, sin que la nota del «servicio» quite ni añada nada al mismo.

\section{El régimen especial de la Ley de consumidores y usuarios}

a) La Ley de consumidores y usuarios pareció obedecer, a primera vista, al designio legislativo de atribuir un genuino «régimen especial» a la responsabilidad por productos y por servicios.

Y si digo pareció es porque, en realidad, y salvo la particularidad de las reglas del artículo 28 , a las que luego me referiré, en todo lo de-

40 Sobre este concreto problema escribió PANTALEÓn PRIETO, F.: La responsabilidad civil de los auditores: extensión, limitación, prescripción, Madrid, Civitas, 1996. Yo me ocupé de la cuestión, en un sentido más amplio, en Responsabilidad por informar, dentro (págs. 171 a 203) del libro colectivo Perfiles de la responsabilidad civil en el nuevo milenio (coordinador Juan Antonio Moreno Martínez), Madrid, Dykinson, 2000. 
más aquella Ley —en lo que a responsabilidad se refiere- no añadió nada nuevo, a mi juicio, a lo que ya venía siendo el acervo jurídico en la materia.

No es cuestión de entrar en un juicio sobre la Ley de consumidores y usuarios, sobre cuyo particular motivo y sobre cuya elaboración todos tenemos información suficiente. Lo único que ahora corresponde señalar es que, en su mayor parte, está constituida por un conjunto de normas dirigidas a reglamentar lo que, para evitar los prolijos términos de la Ley, llamaremos fabricación y distribución de productos y prestación de servicios.

En cuanto tales, esas normas, no son reglas de responsabilidad. Se trata de mandatos que, en su conjunto, no tienen otra finalidad ni otro alcance que el de ordenar las respectivas actividades económicas de productos y servicios, precisando o concretando así un «marco de deberes» a cargo de quienes fabrican o distribuyen los productos, o prestan los servicios. Se introduce de esta manera en nuestro ordenamiento, por vía normativa, un conjunto de reglas de conducta que, de otro modo, el intérprete (sobre todo el juzgador) tendría que extraer de la exégesis de las parcas normas (felizmente parcas, a mi juicio) que en nuestro Derecho regulan la figura del contrato, en general, o las concretas figuras contractuales mediante las que se articula en la vida económica el fenómeno de la adquisición de bienes y servicios.

b) Las reglas sobre responsabilidad, en sentido estricto, se encuentran en el capítulo VIII, rotulado «Garantías y responsabilidades». Y más concretamente, en sus artículos 25 a 28.

Sucede, no obstante, que las normas de los artículos 25 y 26 no constituyeron ninguna novedad en lo que de hecho ya estaba siendo, aunque en algunos extremos por obra de la jurisprudencia, parte del acervo jurídico al que antes me he referido.

Conviene recordar el texto de esos artículos:

«Artículo 25. El consumidor y el usuario tienen derecho a ser indemnizados por los daños y perjuicios demostrados que el consumo de bienes o la utilización de productos o servicios les irroguen salvo que aquellos daños y perjuicios estén causados por su culpa exclusiva o por la de las personas de las que deba responder civilmente.

Artículo 26. Las acciones u omisiones de quienes producen, importan, suministran o facilitan productos o servicios a los consumidores o usuarios, determinantes de daños o perjuicios a los mismos, darán lugar a la responsabilidad de aquéllos, a menos que conste o se acredite que se han cumplido debidamente las exigencias y requisitos reglamentariamente establecidos y los demás cuidados y diligencias que exige la naturaleza del producto, servicio o actividad.» 
De estas reglas se desprende que el empresario sólo responde si en su conducta ha habido culpa. Es decir, no hay ninguna novedad respecto al principio general del artículo 1.902 .

No obstante, se formula un principio de inversión de la carga de la prueba. Pero tampoco aquí cabe apreciar ninguna novedad, porque tal principio se había instalado ya hacía décadas en nuestro Derecho, por obra de una jurisprudencia que, por conocida, exime de mayores comentarios.

Debe advertirse, además, que el régimen de los artículos 25 y 26 puede considerarse «regresivo» (o al menos sólo aplicable al ámbito de lo contractual), porque en dichos preceptos sólo se contempla como víctima al consumidor y usuario, no a terceros ${ }^{41}$. Lo que no significa, desde luego, que un tercero perjudicado, no vinculado con el suministrador por una relación contractual, no pueda demandarle bajo el régimen común de la responsabilidad extracontractual del Código civil.

De lo anterior se desprende que el sistema de responsabilidad del prestador de servicios, según la Ley de consumidores y usuarios, no parece apartarse de los criterios de enjuiciamiento que derivarían del régimen general del Código civil.

Cabe preguntarse incluso si la regla del artículo 26 de la Ley es compatible con el principio jurisprudencial, formulado en principio para todas las actividades de profesionales ${ }^{42}$, pero aplicado sobre todo a los médicos, según el cual «en las actividades de los profesionales, en general, queda descartada la presunción de culpa y, por consiguiente, la inversión de la carga de la prueba». Este criterio sigue estando presente en la jurisprudencia (si bien, en el caso de reclamaciones contra médicos, mitigado por la adopción de paliativos como son el recurso a la «culpa virtual», a la regla res ipsa loquitur o al razonamiento - por cierto, y dicho sea de paso, de tan peligrosa aplicación- basado en el llamado «resultado desproporcionado» ${ }^{43}$ ).

41 Parece innecesario recordar que consumidor o usuario, a efectos de esta Ley, es sólo el destinatario final, según definición del artículo 1.2. Quiere decir que la protección legal no alcanza a quienes profesionalmente adquieran o utilicen bienes o servicios con el fin de integrarlos en procesos de producción, transformación, comercialización o prestación a terceros.

${ }^{42}$ Utilizo esta expresión (de profesionales) porque hablar de actividades profesionales puede inducir a error, por cuanto estas últimas palabras podrían predicarse de cualquiera que presta un servicio, aunque no sea el de un profesional en la acepción social de esta palabra.

${ }^{43}$ No me resisto a reproducir lo que, en relación con este criterio del «resultado desproporcionado», se manifestó en el voto particular emitido en la sentencia de 31 de enero de 2003. El autor de ese voto particular, con razonamiento que comparto plenamente, dijo: "En cuanto a la doctrina jurisprudencial del "resultado desproporcionado" como elemento que justifica una inversión de la carga de la prueba desplazando sobre el médico o cirujano demandado la demostración de su propia diligencia, es necesario precisarla en sus 
c) Distinto es el caso de la responsabilidad por servicios - ya no cabe hablar de productos- susceptibles de integrarse en la previsión normativa del artículo 28 de la Ley de consumidores.

Sus dos primeros apartados rezan:

«1. No obstante lo dispuesto en los artículos anteriores, se responderá de los daños originados en el correcto uso y consumo de bienes y servicios, cuando por su propia naturaleza o estar así reglamentariamente establecido, incluyan necesariamente la garantía de niveles determinados de pureza, eficacia o seguridad, en condiciones objetivas de determinación y supongan controles técnicos, profesionales o sistemáticos de calidad, hasta llegar en debidas condiciones al consumidor o usuario.

2. En todo caso, se consideran sometidos a este régimen de responsabilidad los productos alimenticios, los de higiene y limpieza, cosméticos, especialidades y productos farmacéuticos, servicios sanitarios, de gas y electricidad, electrodomésticos y ascensores, medios de transporte, vehículos a motor y juguetes y productos dirigidos a los niños.»

\footnotetext{
justos términos como una técnica correctora que exime al paciente de tener que probar el nexo causal y la culpa de aquéllos cuando el daño sufrido no se corresponda con las complicaciones posibles y definidas de la intervención enjuiciada. De ahí que, con arreglo a esa misma doctrina, no pueda calificarse de "resultado desproporcionado" el daño indeseado o insatisfactorio pero encuadrable entre los riesgos típicos de la intervención, esto es, entre las complicaciones que sean posibles aun observando el cirujano toda la diligencia exigible y aplicando la técnica apropiada. Y es que, en definitiva, la responsabilidad del cirujano en virtud del art. 1902 del CC sólo puede fundarse en su culpa o negligencia: por eso habrá de responder incluso del riesgo típico si el daño se debió a su actuación descuidada o a la aplicación de técnicas inapropiadas (TS SS 26 de noviembre de 2001 en Rec. 2245/96 y 11 de abril de 2002 en recurso núm. 3422/96), pero en cambio no lo hará de ningún daño, por desproporcionado que parezca, si prueba que no fue debido a su negligencia (TS SS 20 de marzo de 2001 en recurso núm. 567/96 y 23 de marzo de 2001 en recurso núm. 954/96); y por eso, también, responderá civilmente el cirujano que, decidiendo intervenir a un enfermo terminal, no aplique una técnica adecuada o descuide la atención en el postoperatorio, adelantando con ello la muerte del paciente o aumentando su sufrimiento antes de morir (TS S 11 de abril de 2002 en recurso núm. 3422/96). De otro modo, es decir, si se cae en un excesivo reduccionismo que minimice el elemento de la culpa embebiéndolo en el nexo causal, como igualmente podría hacerse, dando un paso más, en el de la acción u omisión, se desvaloriza esta materia hasta despojarla de lo que para nuestro Derecho civil constituye la clave del juicio de responsabilidad. Pues bien, de someter los hechos probados a las anteriores consideraciones jurídicas resulta la desestimación de los dos motivos examinados, porque si la técnica quirúrgica aplicada por el demandado fue la adecuada y no la alegada en la demanda como desfasada, si la intervención no dañó el nervio del esfinter, si la lesión muscular del esfínter externo es consustancial o inherente a la técnica quirúrgica aplicada y si, en fin, los trastornos esfinterinos no son descartables tras este tipo de intervenciones, influyendo en ellos factores incluso psicológicos, la imputación del daño al cirujano demandado como "resultado desproporcionado" equivale a hacerle responsable de un riesgo típico pese a haber probado lo correcto de su intervención; en suma, a identificar riesgo típico con resultado desproporcionado.»
} 
En relación con estas normas, cabe decir:

Según interpretación mayoritaria, en ellas se instaura un criterio de responsabilidad objetiva. Es decir, el prestador de los servicios afectados responde, abstracción hecha de si en su proceder ha mediado o no culpa.

En segundo lugar, se ha puesto de relieve por la doctrina más solvente la imprecisión de los términos utilizados en el apartado 1 para definir los servicios sometidos a ese régimen de responsabilidad objetiva.

En tercer lugar, no faltan argumentos para sostener que, a diferencia de lo que ocurre con los artículos 25 y 26, en este 28 se está dando cobertura al daño sufrido por cualquier perjudicado, esto es, sea o no consumidor o usuario en los términos de la Ley (es decir, destinatario final).

En efecto, si bien al final del apartado 1 se alude al consumidor o usuario, es perfectamente sostenible -incluso con el simple criterio de interpretación gramatical- que la expresión «hasta llegar en debidas condiciones al consumidor o usuario» no es sino una forma o referencia más de definir, por vía descriptiva, los productos y servicios a los que el precepto quiere dotar de un régimen especial de responsabilidad.

Como es sabido, la jurisprudencia viene haciendo un abundante uso de las normas del artículo 28 en lo que a prestación de servicios se refiere. Abundante ilustración se encuentra en la no menos copiosa bibliografía sobre la Ley que ahora me ocupa.

Particular mención merece la jurisprudencia que, aunque con excepciones, extiende el principio de responsabilidad objetiva a la actividad profesional del médico ${ }^{44}$.

En este punto, creo oportuna la cita de la sentencia de 31 de enero de 2003, que he mencionado antes a otros efectos.

En un pasaje, la Sala razona de la siguiente manera:

«A lo anterior debe sumarse la aplicación de la responsabilidad objetiva que respecto a los daños causados por servicios sanitarios establece el artículo 28 de la L 26/1984, de 19 de julio, general para la defensa de consumidores y usuarios y que ha sido reiterada por esta Sala en unas primeras SS 1 de julio de 1997 y 21 de julio de 1997, en la posterior de 9 de diciembre de 1998 y en la reciente de 29 de noviembre de 2002 que dice: "... demandante es consumidor (artículo 1), ha utilizado unos servicios (artículo 26), entre los que se incluyen los sanitarios (artículo 28.2) y la producción de un daño genera responsabilidad objetiva que desarrolla el capítulo VIII (artículos 25 y ss.). Esta responsabilidad de carácter objetivo cubre los daños originados en el correcto uso de los servicios, cuando por su propia naturaleza, o estar así reglamentariamente estable-

44 Traté sobre esta cuestión en mi obra Responsabilidad civil por actos médicos. Problemas de prueba, Madrid, Civitas, 1999, págs. 191-231. 
cido, incluyen necesariamente la garantía de niveles determinados de pureza, eficacia o seguridad, en condiciones objetivas de determinación y supongan controles técnicos, profesionales o sistemáticos de calidad, hasta llegar en debidas condiciones al usuario. Estos niveles se presuponen para el servicio sanitario, entre otros. Producido y constatado el daño... se dan las circunstancias que determinan aquella responsabilidad”. . ${ }^{45}$

Pero discrepó de este modo de pensar el Magistrado autor de un voto particular, con cuyo contenido me muestro totalmente de acuerdo.

Decía ese voto particular:

«A) Aunque ciertamente algunas sentencias de esta Sala han aplicado el artículo 28 de la Ley General para la Defensa de los Consumidores y Usuarios como fundamento de la responsabilidad civil en el ámbito médico y hospitalario, no es menos cierto que la jurisprudencia, entendida como criterio constante y reiterado en la decisión de casos semejantes, rechaza abiertamente la responsabilidad objetiva del médico o del cirujano, esto es, su obligación de indemnizar tan sólo porque el resultado de su intervención no sea el deseado o agrave el estado del paciente, pues en la doctrina de esta Sala la prestación del médico se configura como una obligación de medios y no de resultado, salvo en los casos de medicina no curativa sino voluntaria o satisfactiva (TS SS 31 de julio de 1996, 10 de diciembre de 1996, 25 de enero de 1997, 20 de junio de 1997, 29 de mayo de 1998, 19 de junio de 1998, 12 de marzo de 1999, 18 de setiembre de 1999, 23 de octubre de 2000, 20 de noviembre de 2000, 20 de marzo de 2001, 18 de octubre de 2001, 4 de febrero de 2002 y 25 de junio de 2002, por citar únicamente dos sentencias de cada año).

B) La aplicación simultánea o acumulada de dicho precepto y del artículo 1.902 del CC es difícil de justificar, porque si la responsabilidad que aquél establece se entiende objetiva o por el resultado y la regulada por éste se funda en la culpa o negligencia, como inequívocamente dispone su texto y constantemente declara la jurisprudencia, esa aplicación acumulada equivale a sostener algo tan contradictorio como que la responsabilidad del médico es al mismo tiempo objetiva y subjetiva.

C) Por ende, es más que dudoso que la expresión "servicios sanitarios" del artículo 28 LGDCU comprenda necesariamente la prestación individual médica o quirúrgica e incluso que, de considerarla incluida, la responsabilidad del médico pueda calificarse sin más de objetiva, porque si el apartado 2 de dicho precepto, que es el que se refiere a tales "servicios", se pone en relación con su apartado 1, como

45 Señalo que este recurso a la Ley de consumidores y usuarios es «añadido» a los argumentos que inmediatamente antes había utilizado la sentencia para llegar a su fallo condenatorio. Argumentos que giraban en torno a la llamada doctrina del «resultado desproporcionado» y sobre el principio de la «facilidad probatoria». A mi juicio, acudir, como lo hace la sentencia, al artículo 28 de la Ley de consumidores y usuarios, puede ser revelador de la poca convicción de la Sala sobre los argumentos previamente esgrimidos por ella. 
parece obligado, siempre quedarán por identificar adecuadamente tanto la "garantía de niveles determinados de pureza, eficacia o seguridad, en condiciones objetivas de determinación" como los "controles de calidad”, naturalmente exigibles o reglamentariamente establecidos, que el médico o cirujano demandado hubiera desconocido en su intervención. Es más, la superposición de los dos regímenes de responsabilidad conduce inevitablemente a una consecuencia en sí misma tan indeseable e injustificable, incluso en el plano puramente práctico, de acabar midiendo por el mismo rasero al médico diligente que al negligente, al cuidadoso que al descuidado, en cuanto ambos responderían siempre y por igual de cualquier resultado no deseado de su intervención.»

\section{Responsabilidad del suministrador de productos}

1. Inaplicabilidad de la Ley de consumidores y usuarios a casos de daños causados por productos defectuosos. La disposición final primera de la Ley de productos defectuosos

Dado que, como veremos en seguida, el suministrador de un producto puede ser responsable de acuerdo con la Ley de productos defectuosos, procede en primer término recordar que la disposición final primera de esta última Ley decretó la no aplicabilidad de la Ley de consumidores y usuarios a los supuestos sometidos a aquélla.

Dice esa disposición final:

«Los artículos 25 a 28 de la Ley 26/1984, de 19 de julio, General para la Defensa de los Consumidores y Usuarios, no serán de aplicación a la responsabilidad civil por daños causados por productos defectuosos incluidos en el artículo 2 de la presente Ley.»

Debo insistir en que esta observación, y todo lo que sigue en torno a ella, tiene su razón de ser en una de las dos perspectivas desde las que puede ser contemplada la responsabilidad del suministrador de productos en el momento actual; esto es, como mero suministrador y como empresario que desarrolla actividades distintas del puro suministrar. Pero sobre esta distinción, y su relieve jurídico, trataré más adelante.

2. Esa inaplicabilidad ha sido declarada también por el Tribunal de Justicia de las Comunidades Europeas.

La Directiva de 25 de julio de 1985 no es «de mínimos»

Es oportuno también traer a colación la sentencia del Tribunal de Justicia (Sala Quinta) de 25 de abril de 2002 en el caso María Victoria González Sánchez c. Medicina Asturiana S.A. 
Se dictó en la cuestión prejudicial planteada por el Juzgado de Primera Instancia e Instrucción número 5 de Oviedo. guiente:

El caso, tal y como lo describe la propia sentencia, había sido el si-

«La Sra. González Sánchez recibió una transfusión de sangre en un establecimiento sanitario propiedad de Medicina Asturiana. La sangre utilizada par la transfusión había sido tratada por un centro de transfusiones.

La Sra. González Sánchez sostiene que, a raíz de la transfusión, resultó contagiada por el virus de la hepatitis C. Reclama a Medicina Asturiana, basándose en las disposiciones generales del Código civil español y en los artículos 25 a 28 de la Ley 26/1984, una indemnización por los daños causados. Medicina Asturiana niega que los mencionados artículos de la Ley 26/1984 sean aplicables, habida cuenta de la disposición final primera de la Ley 22/1994.

El juez remitente considera probado que los hechos que originaron el litigio se incluyen en el ámbito de aplicación material y temporal tanto de la Ley 26/1984 como de la Ley 22/1994.

Tras efectuar un análisis de ambos textos legales, el órgano jurisdiccional remitente llegó a la conclusión de que los derechos que los consumidores y los usuarios pueden invocar con arreglo a la Ley 26/1984 son más amplios que los que poseen los perjudicados conforme a la Ley 22/1994 y que, en consecuencia, la adaptación del Derecho interno a la Directiva efectuada por esta última Ley supuso que se redujeran los derechos de que disfrutaban los interesados en el momento de la notificación de dicha Directiva.

Por estimar que en el litigio se suscita una cuestión relativa a la interpretación del artículo 13 de la Directiva, el Juzgado de Primera Instancia e Instrucción número 5 de Oviedo decidió suspender el procedimiento y plantear al Tribunal de Justicia la siguiente cuestión prejudicial: ¿El artículo 13 de la Directiva 85/374/CEE del Consejo, de 25 de julio, relativa a la aproximación de las disposiciones legales, reglamentarias y administrativas de los Estados miembros en materia de Responsabilidad por los Daños causados por Productos Defectuosos, debe interpretarse en el sentido de que impide que, a consecuencia de la transposición de la Directiva, se limiten o restrinjan los derechos que los consumidores tuvieran reconocidos conforme a la legislación del Estado miembro?»

La sentencia, en un primer pasaje, declara:

«De lo anterior se deriva que el margen de apreciación de que disponen los Estados miembros para regular la responsabilidad por los daños causados por productos defectuosos se fija exclusivamente en la propia Directiva, por lo que, para determinar dicho margen, debe estarse al tenor, objeto y sistema de ésta. 
A este respecto, procede destacar en primer lugar que, tal como se desprende de su primer considerando, la Directiva, al establecer un régimen armonizado de responsabilidad civil de los productores por los daños causados por productos defectuosos, pretende garantizar una competencia no falseada entre los operadores económicos, facilitar la libre circulación de las mercancías y evitar que existan diferentes grados de protección de los consumidores.

En segundo lugar, debe señalarse que, a diferencia, por ejemplo, de la Directiva 93/13/CEE del Consejo, de 5 de abril de 1993, sobre las cláusulas abusivas en los contratos celebrados con consumidores (DO L 95, p. 29), la Directiva no contiene ninguna disposición que autorice expresamente a los Estados miembros a adoptar o a mantener, en las materias que regula, disposiciones más estrictas para garantizar a los consumidores un grado de protección más elevado.

En tercer lugar, ha de observarse que el hecho de que la Directiva prevea ciertas excepciones o se remita en algunos aspectos al Derecho nacional no significa que, en las materias que regula, la armonización no sea completa.

En efecto, si bien los artículos 15, apartado 1, letras a) y b), y 16 de la Directiva permiten que los Estados miembros se aparten de las normas que aquélla prevé, esta posibilidad de introducir excepciones sólo es posible en algunos aspectos taxativamente enumerados y se concibe en términos estrictos. Además, tal posibilidad queda supeditada, en particular, a requisitos de evaluación, con el fin de obtener la mayor armonización a la que se refiere expresamente el penúltimo considerando de la Directiva. Como ejemplo de este sistema de armonización evolutiva cabe citar la Directiva 1999/34/CE del Parlamento Europeo y del Consejo, de 10 de mayo de 1999, por la que se modifica la Directiva 95/374 (DO L 141, p. 20), que al incluir los productos agrícolas en el ámbito de aplicación de la Directiva, suprimió la opción abierta por el artículo 15, apartado 1, letra a), de ésta.

En estas circunstancias no puede interpretarse el artículo 13 de la Directiva en el sentido de que deja a los Estados miembros la posibilidad de mantener un régimen general de responsabilidad por los danos causados por productos defectuosos distinto del previsto en la Directiva.

La referencia del artículo 13 de la Directiva a los derechos que el perjudicado pueda tener con arreglo a las normas sobre responsabilidad contractual o extracontractual debe interpretarse en el sentido de que el régimen previsto por dicha Directiva, que, conforme a su artículo 4 , permite al perjudicado solicitar una indemnización siempre que pruebe la existencia del daño, el defecto del producto y la relación de causalidad entre el defecto y el daño, no excluye la aplicación de otros regímenes de responsabilidad contractual o extracontractual que se basen en fundamentos diferentes, como la obligación de saneamiento por vicios ocultos o la culpa.» 
Se advierte el alcance de estas manifestaciones, sobre todo de las contenidas en los dos últimos párrafos que se acaban de transcribir.

Por eso, poco más adelante, la sentencia vuelve a puntualizar:

«Por lo tanto, procede responder a la cuestión planteada que el artículo 13 de la Directiva debe interpretarse en el sentido de que los derechos que los perjudicados por los daños causados por productos defectuosos tuvieran reconocidos conforme a la legislación de un Estado miembro, en virtud de un régimen general de responsabilidad que tenga el mismo fundamento que el establecido por esta Directiva, pueden verse limitados o restringidos como consecuencia de la adaptación del ordenamiento jurídico interno de dicho Estado a lo dispuesto en la mencionada Directiva.»

De ahí el fallo de la sentencia que nos ocupa, que dice:

«El artículo 13 de la Directiva 85/374/CEE del Consejo, de 25 de julio de 1985, relativa a la aproximación de las disposiciones legales, reglamentarias y administrativas de las Estados miembros en materia de responsabilidad por los daños causados por productos defectuosos, debe interpretarse en el sentido de que los derechos que los perjudicados por los daños causados por productos defectuosos tuvieran reconocidos conforme a la legislación de un Estado miembro, en virtud de un régimen general de responsabilidad que tenga el mismo fundamento que el establecido por esta Directiva, pueden verse limitados o restringidos como consecuencia de la adaptación del ordenamiento jurídico interno de dicho Estado a lo dispuesto en la mencionada Directiva.»

Por lo tanto, la sentencia, poniendo fin al debate doctrinal anterior a la Ley de productos defectuosos, sienta al principio de que la Directiva no es «de mínimos», circunstancia que hace que los Estados miembros no puedan mantener normas nacionales que resulten más protectoras para los consumidores (o en su caso más beneficiosas para las fabricantes). Los Estados sólo pueden regular los aspectos expresamente previstos en la propia Directiva y dentro de sus límites ${ }^{46}$.

Por eso, no se puede compartir en modo alguno, a mi entender, el pronunciamiento de la Sala Primera en su sentencia de 21 de febrero de 2003.

Se trataba de la demanda formulada por quien había acreditado lesiones en su ojo derecho, entre otras, como consecuencia de la explosión de una botella de cristal que contenía gaseosa. El demandante la había tomado de uno de los estantes de un supermercado el 28 de agosto de 1994. Al depositarla en la cesta estalló, produciéndole las lesiones

46 Son, por ejemplo, los supuestos de los artículos 15.1 .1 a) y b) y 16 de la Directiva. 
referidas. El envase fue identificado como correspondiente a la marca comercial La Casera, habiéndose llevado a cabo el embotellado y su distribución comercial por la mercantil Carbónica Murciana.

Entablada demanda contra La Casera S.A., Carbónica Murciana y la entidad propietaria del supermercado, la Audiencia confirmó la sentencia del Juzgado, que a su vez había condenado a las sociedades La Casera S.A. y Carbónica Murciana a pagar al actor la cantidad de 7.720.000 pesetas, con intereses.

Hay que hacer notar que el hecho ocurrió el 28 de agosto de 1994, poco menos de dos meses después de entrar en vigor la Ley de productos defectuosos. En efecto, su disposición final cuarta determinó que la Ley entraría en vigor el día siguiente al de su publicación en el Boletín Oficial del Estado. Habiendo sido esa publicación el 7 de julio de 1994, la Ley entró en vigor, pues, el 8 de julio de 1994.

Y a su vez, debe ponerse en relación este dato con el contenido de la disposición transitoria única, en la que se dice que «la presente Ley no será de aplicación a la responsabilidad civil derivada de los daños causados por productos puestos en circulación antes de su entrada en vigor. Esta se regirá por las disposiciones vigentes en dicho momento».

Todas estas circunstancias justificaban la aplicabilidad de la Ley de productos defectuosos al caso enjuiciado.

El hecho es que la Sala Primera desestimó el recurso de casación interpuesto por La Casera S.A., diciendo entre otras cosas lo siguiente:

«La tercera impugnación que se integra en el motivo se refiere a la pretendida exculpación del recurrente como fabricante de la botella de gaseosa, pero sucede que, de conformidad al artículo 6 de la Ley que venimos refiriendo de 6 de julio de 1994, quedó suficientemente demostrado que la recurrente fue la fabricante efectiva de dicho producto terminado, propició su puesta en el mercado, sin que concurra presupuesto alguno que pueda llevar a la conclusión de que no resultaba defectuoso desde el mismo momento de su incorporación al tráfico. El artículo 27.1.a) de la Ley General para la Defensa de los Consumidores y Usuarios, de 19 de julio de 1984, atribuye responsabilidad directa a los fabricantes del producto, pues responden tanto de su origen, como de su identidad e idoneidad.

También ha de rechazarse la infracción que se aporta del artículo 13 del Real Decreto 212/1992, de 6 de marzo, de Etiquetado, Presentación y Publicidad de Productos Alimenticios, pues, aparte de tratarse de normativa posterior a los hechos, para nada desvirtúa ni desnaturaliza la responsabilidad extracontractual del artículo 1902 del Código Civil, aplicado al caso de autos. Ha de tenerse en cuenta que en el etiquetado de la botella figuraba la marca La Casera. Resulta decisivo el artículo 27.1.c) de la Ley 26/1984 para la Defensa de Consumidores y 
Usuarios, pues cuando se trata de productos envasados, etiquetados y cerrados con cierre íntegro, responde la firma o razón social que figure en la etiqueta. No probó la recurrente que no fuera titular de la marca La Casera, por lo que resulta responsable (sentencia de 8 de febrero de 1995), ya que tampoco hizo prueba alguna de que hubiera concurrido incorrecta manipulación por tercero.»

Resulta muy poco feliz, a mi juicio, la cita de un artículo de la Ley de consumidores y usuarios que había dejado de ser aplicable el día mismo de la entrada en vigor de la Ley de productos defectuosos, según su disposición final primera, antes vista.

De otra parte, el Tribunal, a mi juicio, no tenía necesidad ninguna de acudir al artículo 27 de la Ley de consumidores y usuarios, visto el régimen de responsabilidad que la Ley de productos defectuosos introdujo, en relación con el fabricante, desde su entrada en vigor.

Por fin, me causa, más que sorpresa vacilación, el hecho de que la demandada condenada Carbónica Murciana no recurriera en casación, siendo así que la sentencia dice que el producto «ha sido elaborado» por La Casera, llevando a cabo Carbónica Murciana el embotellado y su distribución comercial.

De acuerdo con la Ley que nos ocupa, el responsable es sólo el fabricante, esto es, La Casera. Pero, por otra parte, me pregunto si no podía entenderse que los «fabricantes» eran dos (La Casera, del producto, y Carbónica Murciana del «conjunto» constituido por botella y contenido de gaseosa).

Lo pongo de relieve, precisamente en el tema objeto de esta ponencia, porque parece que en las funciones de Carbónica Murciana no estaba sólo la de «distribución comercial», sino también — como queda dicho- una de «fabricación».

Tampoco me parece que pueda compartirse el criterio, siquiera obiter dictum, de la poco posterior sentencia de 14 de julio de 2003.

En esta resolución se reclamaba a la importadora de un automóvil Toyota y a la concesionaria vendedora del mismo la indemnización de los daños personales y materiales sufridos por los actores como consecuencia del vuelco del vehículo, debido a que el eje trasero del mismo presentaba un defecto de fabricación que hacía que con su normal funcionamiento sufriera una fatiga que, a su vez, determinó un progresivo deterioro de su sección; deterioro que acabó produciendo su rotura.

Debe señalarse que el vehículo había sido comprado por los actores el 21 de marzo de 1991, esto es, antes de la entrada en vigor de la Ley de productos defectuosos, por lo que ésta no era de aplicación (me remito de nuevo a la disposición transitoria única de la Ley).

Quiere decir que la aplicable sería la Ley de consumidores y usuarios. 
No obstante, a la sentencia, introduciendo un elemento de juicio innecesario y perturbador, dice en su fundamento de Derecho primero:

«La quaestio iuris se concreta a la responsabilidad derivada del daño causado por producto defectuoso. Hoy está regulada por L 22/1994, de 6 de julio; anteriormente, por la Directiva de la Unión Europea 85/374/CEE, de 25 de julio de 1985 que aquélla traspuso; en España, por los artículos 25 y ss. de la L 26/1984, de 19 de julio, general para la defensa de los consumidores y usuarios. Responsabilidad que la primera de las leyes citadas califica, en la exposición de motivos, de "objetiva, aunque no absoluta, permitiendo al fabricante exonerarse de responsabilidad en los supuestos que se enumeran"; y la Directiva dice: "únicamente el criterio de la responsabilidad objetiva del productor permite resolver el problema, tan propio de una época de creciente tecnicismo como la nuestra, del justo reparto de los riesgos inherentes a la producción técnica moderna"; y de la ley de consumidores y usuarios, la doctrina ha calificado la responsabilidad que contempla el artículo 25, por el consumo de bienes o la utilización de productos o servicios al consumidor, de relativamente objetiva y la que establece el artículo 28 para ciertos productos, entre los que se hallan los vehículos de motor, de objetiva pura. Cuya responsabilidad objetiva es mantenida explícitamente y como fundamento del fallo en la sentencia de 5 de octubre de 1999 que la apreció en un caso de daño causado por producto farmacéutico, que se contempla en el artículo 28.2. de la Ley de consumidores y usuarios junto a los vehículos de motor.»

No parece necesario extenderse demasiado para concluir que esta cita de dos leyes (entre sí «incompatibles» desde el punto de vista normativo) no fue precisamente un acierto.

3. El «sistema» de responsabilidad de la Ley de productos defectuosos

A modo de simple recordatorio, conviene retener que:

La Ley establece un sistema de responsabilidad objetiva, aunque no absoluta, permitiendo al fabricante exonerarse de responsabilidad en los supuestos que se enumeran. Así lo dice la Exposición de motivos. El principio de responsabilidad objetiva se extrae del artículo 1, en el que no hay mención alguna a un criterio de imputación por culpa. Las causas de exoneración son las del artículo 6.

Como advierte la doctrina más cualificada y reciente ${ }^{47}$, «cabe señalar que el régimen establecido en la Directiva 85/374/CEE y en sus

47 Martín Casals, M. y Solé i Feliu, J., «Veinte problemas en la aplicación de la Ley de responsabilidad por productos defectuosos y algunas propuestas de solución (I)», en Práctica Derecho de daños, año I, número 9, págs. 6 ss. 
respectivas leyes internas de transposición es de responsabilidad objetiva. La naturaleza de ese régimen no se altera por el hecho de que la propia Directiva admita ciertas causas de exoneración. Aunque puedan existir debates doctrinales sobre la relación de alguna de esas causas con una pretendida relevancia de la culpa que haría mella en el régimen de la responsabilidad objetiva, lo que resulta claro es que el causante del daño no podrá exonerarse con la prueba de haber actuado con la diligencia debida».

La responsabilidad es por daños causados por un producto defectuoso, lo que significa que los daños del propio producto no están bajo la cobertura de esta Ley (artículo 10.1). Por tanto, por volver a usar una expresión que he utilizado antes, la responsabilidad es por daños por el producto y no en el producto.

La responsabilidad a la que se refiere la Ley es porque el producto es defectuoso (en los términos del artículo 3), no porque sea peligroso. El concepto de «defecto» se anuda a la falta o deficiencia de la seguridad que cabría esperar del producto.

Son responsables los fabricantes y los importadores. Estos últimos, en los términos en que son definidos en el artículo 4.2.

También es responsable, en determinado caso, el suministrador. Pero de esto me ocupo más adelante, como es lógico.

Debe resaltarse que, en virtud de lo que manifiesta la Exposición de motivos (no el articulado), «los sujetos protegidos son, en general, los perjudicados por el producto defectuoso, con independencia de que tengan o no la condición de consumidores en sentido estricto». Es decir, no se sigue el criterio del «destinatario final» de la Ley de consumidores y usuarios.

El perjudicado tendrá que probar el defecto, el daño y la relación de causalidad entre ambos.

Los responsables del mismo daño "por aplicación de la presente Ley», dice el artículo 5, en importante puntualización que subrayo, lo serán solidariamente.

Según el artículo 8, «la responsabilidad del fabricante o importador no se reducirá cuando el daño sea causado conjuntamente por un defecto del producto y por la intervención de un tercero». Regla importante en la materia que me ocupa, porque es muy verosímil que la «intervención de un tercero» pueda ser la constituida por la actuación del suministrador; por ejemplo, en sus funciones de conservar o manipular el producto.

No obstante, el segundo inciso del mismo artículo 8 hace la advertencia de que «el sujeto responsable de acuerdo con esta Ley que hubiera satisfecho la indemnización podrá reclamar al tercero la parte que corresponda a su intervención en la producción del daño». 
De acuerdo con el artículo 9, «la responsabilidad del fabricante o importador podrá reducirse o suprimirse en función de las circunstancias del caso, si el daño causado fuera debido conjuntamente a un defecto del producto y a culpa del perjudicado o de una persona de la que éste deba responder civilmente».

El artículo 10, bajo la rúbrica «ámbito de protección», declara en primer lugar que el régimen de responsabilidad civil previsto en la Ley comprende los supuestos de muerte y las lesiones corporales, así como los daños causados en cosas distintas del propio producto defectuoso, siempre que la cosa dañada se halle objetivamente destinada al uso o consumo privados y en tal concepto haya sido utilizada principalmente por el perjudicado.

Los demás daños y perjuicios, incluidos los daños morales, podrán ser resarcidos conforme a la legislación civil general. Téngase muy presente esta regla, que permitirá al perjudicado reclamar al fabricante o importador (y en su caso al suministrador, como luego veremos) la totalidad de los daños, si bien - respecto a los que no entran dentro del ámbito de la Ley - bajo la fórmula procesal de la acumulación objetiva de acciones y con fundamento en el régimen general del Código civil ${ }^{48}$.

El artículo 12 determina que la acción de reparación de los daños y perjuicios previstos en la Ley prescribirá a los tres años, a contar desde la fecha en que el perjudicado sufrió el perjuicio, ya sea por defecto del producto o por el daño que dicho defecto le ocasionó, siempre que se conozca al responsable de dicho perjuicio.

Son ineficaces frente al perjudicado (artículo 14) las cláusulas de exoneración o de limitación de la responsabilidad civil prevista en la Ley.

Merece especial mención, por su posible importancia a efectos del objeto de este trabajo, el artículo 15, que reza: «Las acciones reconocidas en esta Ley no afectan a otros derechos que el perjudicado pueda tener como consecuencia de la responsabilidad contractual o extracontractual del fabricante, importador o de cualquier otra persona».

\section{Menciones legales de la responsabilidad del suministrador}

Como no podía menos de ser, he dejado para un apartado especial las menciones que la Ley hace a la responsabilidad del suministrador.

48 Recuérdese que la sentencia del Tribunal de Justicia de la hoy Unión Europea de 25 de abril de 2002, antes examinada, declara que el artículo 13 de la Directiva (15 de la Ley española) «no excluye la aplicación de otros regímenes de responsabilidad contractual o extracontractual que se basen en fundamentos diferentes, como la obligación de saneamiento por vicios ocultos o la culpa». 
En primer lugar, el artículo 4.3 establece:

«3. Si el fabricante del producto no puede ser identificado, será considerado como fabricante quien hubiere suministrado o facilitado el producto, a menos que, dentro del plazo de tres meses, indique al dañado o perjudicado la identidad del fabricante o de quien le hubiera suministrado o facilitado a él dicho producto. La misma regla será de aplicación en el caso de un producto importado, si el producto no indica el nombre del importador, aun cuando se indique el nombre del fabricante.»

Por otro lado, la inexplicable (en todos los sentidos) disposición adicional única reza:

«Unica. Responsabilidad del suministrador

El suministrador del producto defectuoso responderá, como si fuera el fabricante o el importador, cuando haya suministrado el producto a sabiendas de la existencia del defecto. En este caso, el suministrador podrá ejercitar la acción de repetición contra el fabricante o importador.»

5. Las dos vertientes en las que puede manifestarse la responsabilidad del suministrador de productos, una en el marco de la Ley y otra en el del régimen general de responsabilidad del Código civil

Dejando de lado deliberadamente la a mi juicio lamentable disposición adicional única ${ }^{49}$, me parece que el análisis de las diversas hipótesis posibles conduce a dos grandes supuestos o grupos de supuestos.

(i) En primer lugar, el constituido por el caso que de forma muy precisa y taxativa describe el artículo 4.3. Es la hipótesis en la que (i) el fabricante del producto no puede ser identificado y (ii) el suministrador, dentro del plazo de tres meses, no indica al dañado o perjudicado la identidad del fabricante o de quien le hubiere suministrado o facilitado a él el producto. En estas circunstancias, «quien hubiere suministrado o facilitado el producto» — el suministrador, en suma— «será considerado como fabricante»; palabras estas últimas, en realidad constitutivas de

49 Lamentable, en primer lugar, porque no se entiende a santo de qué su singular norma. Y en segundo término, porque la hipótesis de suministro de un producto «a sabiendas de la existencia del defecto» es, desde la perspectiva contractual, de un lado, un supuesto de dolo, entendido este concepto como vicio del consentimiento (artículo 1.269 del Código civil) que determina la anulabilidad del contrato (artículo 1.300); y de otra parte, un caso manifiesto de incumplimiento por dolo (artículo 1.101 del Código civil, en relación con el 1.102) en sede de la que denominamos responsabilidad contractual (o dicho de otro modo, lesión del derecho de crédito). 
una ficción, que asignan al suministrador la misma responsabilidad que la que al fabricante incumbiría (o mejor dicho, incumbe). Esto, en cuanto al primer inciso del apartado 3 .

Por lo que respecta al segundo, la hipótesis es la de que (i) el producto es importado, (ii) el producto no indica el nombre del importador, aunque sí indique el del fabricante y (iii) el suministrador, dentro del plazo de tres meses, no indica al dañado o perjudicado la identidad del importador. En estas circunstancias, el suministrador «será considerado por el fabricante», esto es, responderá como si del fabricante se tratase. $Y$ es esto último, en cuanto al segundo inciso del mismo apartado 3 del artículo 4.

A mi juicio, la forma en que el suministrador es contemplado en estas reglas permite hacer (o mejor dicho obliga a hacer) una distinción que determina la aplicación de un régimen legal o de otro.

De acuerdo con ella, un primer caso es el del suministrador cuya actividad es exclusivamente ésa, la de suministrar (aunque parezca una tautología), siendo así que, además, de hecho no realiza actividad alguna que sea la causa -única o concurrente con un defecto de fabricación- del defecto del producto.

En esta hipótesis, el suministrador responde únicamente si se dan las circunstancias del apartado 3 del artículo 4, esto es, las de no notificar al perjudicado la identidad del fabricante (o de quien le hubiera suministrado o facilitado a él el producto), en el caso de producto no importado ${ }^{50}$; o la del importador si se trata de un producto importado.

Si esa falta de notificación o información al perjudicado se produjese, el suministrador responderá. Pero, a mi entender, sólo lo hará en los términos de la Ley. Su responsabilidad será objetiva, existirá si el producto es defectuoso y responderá de los daños precisamente contemplados en el apartado 1 del artículo 10, no de otros. Y, en la medida en que sea imaginable, le serán de aplicación otras reglas de la Ley; por ejemplo, sobre la prueba, sobre causas de exoneración, sobre intervención de un tercero o culpa del perjudicado, sobre prescripción, etc.

Me mueve a pensar así el carácter excepcional que la Directiva comunitaria quiso dar a la responsabilidad del suministrador, patente en su detallada Exposición de motivos y en la jurisprudencia del Tribunal de Justicia.

Parece evidente que si la Directiva (y en definitiva la Ley española) hubieran querido someter al régimen de responsabilidad especial del que estamos hablando cualquier otra conducta del suministrador, dis-

50 Recuérdese el concepto de «importación» que resulta del apartado 2 del mismo artículo 4. 
tinta de la del no indicar o comunicar la identidad del fabricante o la del importador, según los casos, ese imaginario propósito habría encontrado formulación explícita.

Esto, desde luego, sin perjuicio de que el perjudicado opte por demandar al suministrador (junto o no con el fabricante), en tanto en cuanto lo haga - en el caso del suministrador-con amparo en el régimen general de responsabilidad del Código civil ${ }^{51}$.

No siendo así, insisto, parece que debe concluirse en la afirmación que he sostenido.

Es también la opinión sostenida por MARTIN CASALS y SOLE I FELIU (que, por cierto, dicen con gracejo que el suministrador, echado por la puerta, se cuela de rondón por la ventana), al manifestar:

«...la responsabilidad del suministrador en el marco de la Ley de responsabilidad civil por los daños causados por productos defectuosos debe considerarse excepcional. Como ha declarado el Tribunal de Justicia de las Comunidades Europeas, la decisión de excluir prácticamente al suministrador del sistema de responsabilidad de la Directiva forma parte del difícil equilibrio de intereses logrado por el legislador europeo y queda fuera del margen de apreciación de los estados miembros. Por eso, las reglas del artículo 4.3 de la Ley de responsabilidad civil por los daños causados por productos defectuosos y la Disposición Adicional Unica de la Ley de responsabilidad civil por los daños causados por productos defectuosos son excepcionales y, como tales, deben ser objeto de una interpretación restrictiva por parte de los tribunales $^{52}{ }$.

51 No incompatible con la posibilidad de que al fabricante se le demande con fundamento en la Ley de productos defectuosos.

52 Martín Casals, M. y Solé i Feliu, J., «Veinte problemas...», cit., pág. 34. De manera muy oportuna, los autores habían dicho antes: «Desde este punto de vista, hay que tener en cuenta que el Tribunal de Justicia de las Comunidades Europeas ha declarado incorrecta la transposición francesa de la Directiva en lo relativo a los sujetos responsables, porque el artículo 1386-7 Code Civil se apartó del régimen de la Directiva y dispuso la responsabilidad del suministrador en todo caso. En opinión del Tribunal de Justicia de las Comunidades Europeas, determinar quiénes son responsables conforme a la Directiva pertenece a la esfera de intereses que en su momento ponderó el legislador europeo y que, por ese motivo, excluyó del ámbito de apreciación de los Estados miembros. Así al considerar responsable al suministrador más allá del límite fijado por la Directiva, el Tribunal de Justicia de las Comunidades Europeas considera que el legislador francés se excedió, ya que el legislador comunitario era el único competente "para determinar la persona a la que debe imputarse dicha responsabilidad, así como los requisitos para su atribución". Esa directriz fue correctamente comprendida por la ley española de transposición, cuyo artículo 4.3 de la Ley de responsabilidad civil por los daños causados por productos defectuosos reproduce la regla del art. 2.3 Directiva y considera que el suministrador responderá sólo si "el fabricante del producto no puede ser identificado (...) a menos que, dentro del plazo de tres meses, indique al dañado o perjudicado la identidad del fabrican- 
Es de la misma opinión PARRA LUCAN53, cuando dice que en los casos en que el suministrador haya identificado al fabricante $\mathrm{y}$, pese a ello, la demanda se haya dirigido contra el suministrador (porque el fabricante ha desaparecido, o es insolvente), deberá ser desestimada, salvo que el consumidor base su demanda en la culpa o negligencia del vendedor (artículos 1.101 o 1.902 del Código civil).

Participa del mismo criterio YZQUIERDO TOLSADA ${ }^{54}$. El autor lo dice, precisamente, al comentar la ya citada sentencia de 21 de febrero de 2003. También, en el mismo lugar, al referirse a la sentencia de 10 de junio de 2002, que condenó exclusivamente a la empresa distribuidora o comercializadora en España de una golosina de fabricación italiana. Un niño de tres años falleció - parece que por asfixia — después de ingerir una de esas golosinas. Se absolvió a la demandada que regentaba el quiosco en el que el padre del niño había adquirido una bolsa.

Todo lo anterior lleva, pues, a la segunda hipótesis de las que me ocupo en este apartado.

(ii) En segundo lugar, en efecto, se hallan todos aquellos casos en los que (i) la actuación del suministrador hubiere sido la causa de la existencia del defecto (quiere decir, la única causa) o (ii) aquellos en que la conducta del suministrador hubiera sido causa añadida a la previa existencia del defecto del producto (concausa como solemos decir); esto es, si algún defecto existiese en la fabricación pero se incrementase por acción del suministrador.

Es decir, hablamos de dos, valga decir, subhipótesis.

a) Para la primera de ellas (el defecto no es de fabricación), el punto de partida es la circunstancia (curiosa, pero no sorprendente) de que, siendo la responsabilidad de la Ley de productos defectuosos de carácter objetivo (lo que excluye la toma en consideración del elemento cul$p a$ en la acción de fabricar), en cambio sí cabe la indagación sobre si en el producto fabricado - tal y como salió de manos del productorhubo o no defecto.

a.1) Esta posibilidad, que en todo caso vendría impuesta por la lógica más elemental, se encuentra formulada en la Ley cuando, en el

te o de quien le hubiera suministrado o facilitado a él dicho producto. La misma regla será de aplicación en el caso de un producto importado, si el producto no indica el nombre del importador, aun cuando se indique el nombre del fabricante"».

53 «La responsabilidad civil por productos...», pág. 1322.

54 YzQuiERdo Tolsada, M., «Productos defectuosos (y, frente a los daños que los mismos causan), leyes defectuosas y sentencias defectuosas», en Asociación Española de Abogados especializados en responsabilidad civil y seguro, número 7, 2003, págs. 5-23. 
apartado 1 del artículo 6, se enumeran las llamadas «causas de exoneración» del fabricante.

Entre ellas está la consistente en que el fabricante o el importador prueben «que, dadas las circunstancias del caso, es posible presumir que el defecto no existía en el momento en que se puso en circulación el producto».

Quiere decir que el fabricante o el importador responden, en los términos de la Ley, salvo si prueban hechos y datos que induzcan a la presunción ${ }^{55}$ de que el producto fue puesto en circulación por el fabricante sin ser defectuoso.

Habida cuenta, pues, de que el defecto puede ser «sobrevenido», una de las posibilidades (es de suponer que la más frecuente) es la de que el defecto sea consecuencia de la acción de cualquiera de los integrantes de la cadena comercializadora y, por tanto, del último de la misma, esto es, el llamado suministrador final ${ }^{56}$.

a.2) No es cuestión de entrar en detalles acerca de las circunstancias en las que puede ocurrir que el defecto del producto sea causado exclusivamente por la actividad del suministrador.

La doctrina ${ }^{57}$ se refiere a diversos supuestos. Puede tratarse de defectos de conservación, esto es, los que se producen durante la recepción o recogida de la mercancía, el almacenamiento, la exposición al público consumidor o la entrega de los productos, como consecuencia de las condiciones a las que han estado sometidos para

55 Ahora es necesario acudir al artículo 386.1 de la Ley de Enjuiciamiento civil, que, al referirse a las llamadas «presunciones judiciales», dice: «A partir de un hecho admitido o probado, el tribunal podrá presumir la certeza, a los efectos del proceso, de otro hecho, si entre el admitido o demostrado y el presunto existe un enlace preciso y directo según las reglas del criterio humano.»

56 No cabe olvidar, sin embargo, que el defecto puede ser producido por uno de esos miembros o elementos de la cadena y el perjudicado ser otro miembro o elemento posterior; el defecto puede ser producto de la acción del mayorista y ser el minorista el perjudicado, aunque en esta hipótesis es poco probable que se den los daños objeto de cobertura por el régimen especial de la Ley que nos ocupa.

57 Sobre todo, en la monografía de CILlERO DE CABO, P., La responsabilidad civil del suministrador final por daños ocasionados por productos defectuosos, Madrid, Civitas, 2000. Esta autora articula su trabajo sobre la base de distinguir tres hipótesis de responsabilidad del suministrador final de productos. En primer lugar, la específica de la Ley de productos defectuosos, esto es, los ya examinados casos del artículo 4.3 y de la disposición adicional única. En segundo término, la responsabilidad del suministrador final por daños ocasionados por productos que adolecen de defectos que tienen su origen en el proceso de producción. Y en tercer lugar, la hipótesis en la que ahora nos encontramos, esto es, la de responsabilidad del suministrador final por daños ocasionados por productos que adolecen de defectos que tienen su origen (sólo) en el desarrollo de la propia actividad empresarial del suministrador. 
mantenerlos en el mismo estado en que fueron recibidos por el suministrador final ${ }^{58}$.

O puede tratarse de defectos de manipulación, es decir, debidos a actuaciones propias del suministrador e inherentes a la naturaleza del producto. Por ejemplo, actuaciones de montaje o ensamblaje.

Y pueden ser, en fin, defectos de información. Se trata del caso en el que la falta de seguridad del producto se debe a que el suministrador no ha proporcionado información, o lo ha hecho de forma insuficiente o incorrecta, sobre la forma de uso del producto, sus peligros, instrucciones de mantenimiento, etc. Verdad es que no será frecuente que esta circunstancia se dé sin que a la vez exista responsabilidad (también por el capítulo de información) del fabricante. Si esto ocurriera, estaríamos en una hipótesis distinta, subsumible en la siguiente «subhipótesis». Pero no es de descartar la sola responsabilidad del suministrador; imaginemos el caso en el que éste no entrega al adquirente el folleto de instrucciones de uso que el fabricante sí entregó a aquél.

En definitiva, estamos en presencia de un problema en el que, a efectos de cada caso concreto, habrá de ser tomada en consideración, en primer lugar, la naturaleza de la prestación incumbente al suministrador; lo que significa interpretar, y en su caso «integrar» el contrato de cada caso.

a.3) Como es obvio, particular relieve tienen a estos efectos las normas legales en materia de deberes de «seguridad» impuestos a determinados protagonistas del proceso de comercialización.

Es obligada, por eso, la cita del Real Decreto de 26 de diciembre de 2003 sobre seguridad general de los productos. Reproduzco su artículo 1:

«1. El objetivo de este real decreto es garantizar que los productos que se pongan en el mercado sean seguros.

2. Las disposiciones de este real decreto se aplicarán a todo producto destinado al consumidor, incluidos los ofrecidos o puestos a disposición de los consumidores en el marco de una prestación de servicios para que éstos los consuman, manejen o utilicen directamente o que, en condiciones razonablemente previsibles, pueda ser utilizado por el consumidor aunque no le esté destinado, que se le suministre o se ponga a su disposición, a título oneroso o gratuito, en el marco de una actividad comercial, ya sea nuevo, usado o reacondicionado.

3. No obstante lo previsto en el apartado anterior, lo dispuesto en este real decreto no se aplicará a los productos usados que se suministren como antigüedades o para ser reparados o reacondicionados antes de su utilización, siempre que el proveedor informe de ello claramente a la persona a la que suministre el producto.

58 Cillero de Cabo, págs. 326-328. 
4. Cuando para un producto exista una normativa específica que tenga el mismo objetivo y que regule su seguridad, este real decreto sólo se aplicará con carácter supletorio a aquellos riesgos, categorías de riesgos o aspectos no regulados por dicha normativa.

5. Esta disposición se aplicará sin perjuicio de lo establecido en materia de responsabilidad por los daños ocasionados por productos defectuosos, y de las obligaciones que para los empresarios surjan de conformidad con la legislación civil y mercantil en los supuestos de retirada y recuperación de los productos de los consumidores.»

En el artículo 2, de «definiciones», se denomina productor, entre otros, a «los demás profesionales de la cadena de comercialización, en la medida en que sus actividades puedan afectar a las características de seguridad del producto» ${ }^{59}$.

Por ello, es de particular interés el artículo 4, relativo a «deberes de los productores», así como el 6 , sobre «otros deberes de productores y distribuidores».

Y todo esto, desde luego, sin perjuicio de la aplicación de otras normas jurídicas, como puede ser lo que en materia de seguridad de productos se dispone en la Ley de consumidores y usuarios. En particular, en lo que se refiere a la «seguridad» basada en la información, los artículos 3 y 13 .

a.4) Sin embargo, lo dicho hasta ahora para la primera de las dos hipótesis suscita el reparo que a menudo deriva del planteamiento teórico o académico de los problemas.

Me refiero al hecho de que, vistas las cosas como ocurren en la realidad, lo normal será que, sufrido por el perjudicado un daño de los que entran dentro del ámbito de la Ley de productos defectuosos, ese perjudicado - que normalmente carecerá de elementos de juicio para conocer el origen del defecto- demandará al fabricante. Es de suponer que lo hará con base en la Ley de productos defectuosos para los daños cubiertos por ella; y, en su caso, con fundamento en el Código civil para los demás daños.

El fabricante demandado alega que el defecto no existía en el momento en que se puso en circulación el producto, lo que significa que tuvo que ser por la acción de un tercero, eventualmente el suministrador.

Así las cosas, si la alegación del fabricante prospera, la demanda está condenada al fracaso, con lo que esto significa en punto a costas.

59 Interesa señalar que, por el contrario, recibe el nombre de distribuidor «cualquier profesional de la cadena de comercialización cuya actividad no afecte a las características de seguridad de los productos». 
Y al referirme a ellas, se me ocurre que la única posibilidad favorable al demandante es la de que el tribunal no las imponga al actor al amparo del último inciso del apartado 1 del artículo 394 de la Ley de Enjuiciamiento civil («que el caso presentaba serias dudas de hecho o de derecho»). Y para que esto pueda ser apreciado por el tribunal, me parece que éste deberá tomar en consideración la conducta de las partes, sobre todo del demandante, antes de la demanda; por ejemplo, valorar los esfuerzos que el actor pudo haber hecho - antes de demandarpara conocer la causa del defecto, la actitud de silencio o de colaboración del fabricante ante eventuales reclamaciones del actor antes de éste demandar, etc.

Es decir, entiendo que no es imposible, ni difícil, que la sentencia absolutoria del fabricante pueda ser sin condena en costas al actor.

Problema distinto, y muy sugestivo, que me limito a plantear, es la de si tendría cabida en este caso la fórmula de la intervención provoca$d a$ del artículo 14 de la Ley de Enjuiciamiento civil, en su modalidad (la del apartado 2) de iniciativa por parte del demandado.

En primer lugar, está el obstáculo — muy considerable - de que esa forma de intervención provocada es «cuando la ley permita al demandado llamar a un tercero para que intervenga en el proceso». No encuentro ninguna norma sustantiva que lo permita, aunque tampoco me parecería heterodoxa una resolución judicial que lo hiciera. De hecho, conozco el caso en el que el tribunal ha dado cabida a esa intervención provocada a instancias del demandado, en un caso de responsabilidad derivada de la construcción; hipótesis en la que tampoco existe una norma sustantiva que «permita» al demandado hacer lo que previene el citado apartado 2 del artículo 14 de la Ley de Enjuiciamiento civil.

Lo que ocurre es que, en el caso de que esa posibilidad se diera, el tercero (suministrador) «llamado», aunque adquiera la condición procesal de parte, no podría ser condenado, en virtud del principio de congruencia; porque el demandante no ha formulado pretensión alguna contra él.

Lo que, a su vez, plantea la interesante cuestión de si el actor podría ampliar la demanda después de que el fabricante demandado ha evacuado su contestación. En principio, la respuesta parece negativa, a la luz del artículo 401.2 de la Ley procesal, pero me parece que una interpretación lógica permitiría superar el escollo, siempre, desde luego, que se hubiese dado respuesta positiva a la cuestión anterior, esto es, la de si el fabricante puede «llamar» al tercero (insistimos en la figura del suministrador) aun no existiendo una ley que, en palabras del artículo 14, «lo permita». 
Si la intervención provocada de la que acabo de hablar no tuviera cabida, es obvio que al perjudicado no le asistirá otra posibilidad que la de entablar un nuevo pleito contra el suministrador causante del defecto del producto.

b) La segunda «subhipótesis» es la de que la acción del suministrador ha «concurrido» con un previo defecto de fabricación del producto.

La posibilidad de demandar al suministrador tiene su soporte en el artículo 15 de la Ley de productos defectuosos, pero la reclamación a él tiene que fundarse en el régimen general de responsabilidad del Código civil, esto es, en la culpa.

En este caso, lo normal será que, existente el defecto del producto, el perjudicado (salvo que las circunstancias le permitan tener un cabal conocimiento de la causa del defecto) demande al fabricante, en tanto en cuanto le sea favorable el régimen especial de responsabilidad de este último según la Ley de productos defectuosos. Sin perjuicio, insisto una vez más, de que también pueda invocar el régimen de responsabilidad común del Código civil, por ejemplo para daños que no están dentro de la cobertura de la Ley de 1994.

La demanda sólo contra el fabricante podría tener (creo que no) su justificación en el artículo 7 de la Ley, que formula el principio de responsabilidad solidaria. Pero, desde luego, no se me oculta un reparo. Consiste en advertir que ese artículo 7 habla de responsables «por aplicación de la presente Ley». Y debe recordarse que la responsabilidad del suministrador no es por virtud de la Ley especial que nos ocupa, sino en aplicación del Código civil.

Lo que obligaría a acudir a la por otra parte no siempre convincente doctrina jurisprudencial sobre la solidaridad en los casos de producción conjunta de un daño.

Pero, por lo demás, es evidente la posibilidad, e incluso la conveniencia, de que el perjudicado opte por demandar al fabricante, al suministrador, o a ambos, bajo el régimen de responsabilidad común del Código civil, esto es, sobre el criterio de imputación basado en la culpa (si bien con la considerable presencia del principio de inversión de la carga de la prueba). Y esto, por permitirlo también el artículo 15 de la Ley de productos defectuosos, en el sentido que le atribuye la ya citada sentencia del Tribunal de Justicia de la Unión Europea.

Salvo que el criterio de responsabilidad objetiva propio de la Ley de productos defectuosos sea definitivamente tentador, me parece claro que la fórmula de demandar conjuntamente a fabricante y suministrador es la más convincente. De hecho, se observa constantemente en la jurisprudencia. 


\section{Referencia bibliográfica}

La reseña bibliográfica que sigue (y que no siempre se ajusta a la utilizada en el texto) tiene la finalidad de informar sobre obras en las que, de forma más o menos profunda, se alude al tema objeto de este trabajo. Me limito casi exclusivamente a responsabilidad por productos, pues la de servicios se encuentra en la conocida y copiosa bibliografía sobre la Ley general para la defensa de consumidores y usuarios. Por otro lado, me ciño a las obras generales y monografías; y además, a las más recientes.

CILleRo DE CABO, P.: La responsabilidad civil del suministrador final por daños ocasionados por productos defectuosos, Madrid, Civitas, 2000.

De LA VEGA GARCÍA, F.: Responsabilidad civil derivada del producto defectuoso. Un estudio de la Ley 22/1994 en el sistema de responsabilidad civil, Madrid, Civitas, 1998.

FERnÁNDEZ Romo, M.M.: La responsabilidad civil del producto, Madrid, Editoriales de Derecho Reunidas, 1997.

Gómez Calero, J.: Los derechos de los consumidores y usuarios, Madrid, Dykinson, 1994.

Gómez CALERo, J.: Responsabilidad civil por productos defectuosos, Madrid, Dykinson, 1996.

GutiÉRrez SAntiago, P.: Responsabilidad civil por productos defectuosos. Cuestiones prácticas, Granada, Comares, 2004.

IZQUIERDO CARRASCO, M.: La seguridad de los productos industriales (Régimen jurídico-administrativo y protección de los consumidores), Madrid, Marcial Pons, 2001.

JimÉNEZ LIÉBAnA, D.: Responsabilidad civil: Daños causados por productos defectuosos, Madrid, McGraw-Hill, 1998.

Lois Caballé, A. I.: La responsabilidad del fabricante por los defectos de sus productos, Madrid, Tecnos, 1996.

MARÍn LóPEZ, J.J.: Daños por productos: estado de la cuestión, Madrid, Tecnos, 2001.

PARRA LuCÁN, M.A.: Daños por productos y protección del consumidor, Barcelona, Bosch, 1990.

PARRA LuCÁN, M.A.: «La responsabilidad civil por productos y servicios defectuosos. Responsabilidad civil del fabricante y de los profesionales» en Tratado de responsabilidad civil, coordinado por REGLERO CAMPOS, L.F., 2. ${ }^{a}$ edición, Cizur Menor, Aranzadi, 2003, págs. 1267-1358.

Prada Alonso, J.: Protección del consumidor y responsabilidad civil, MadridBarcelona, Marcial Pons, 1998.

REYes LóPEZ, M.J.: Seguridad de productos y responsabilidad del fabricante. Otro supuesto de responsabilidad civil especial: la del fabricante por productos defectuosos, Valencia, Práctica de Derecho, 1998.

ReYes LóPEZ, M.J.: Derecho de consumo (coordinadora), 2. ${ }^{\text {a }}$ edición, Valencia, Tirant lo Blanch, 1999. 
RODRÍGUEZ CARRIÓN, J.L.: La responsabilidad civil por los daños causados por productos defectuosos, Revista General del Derecho, Valencia, 2000.

Rodríguez Llamas, S.: Régimen de responsabilidad civil por productos defectuosos, 2. ${ }^{a}$ edición, Pamplona, Aranzadi, 2002.

RuIz Muñoz, M.: Derecho europeo de responsabilidad civil del fabricante, Valencia, Tirant lo Blanch, 2004.

SolÉ I Feliu, J.: El concepto de defecto del producto en la responsabilidad civil del fabricante, Valencia, Tirant lo Blanch, 1997.

Torralba Mendiola, E.C.: La responsabilidad del fabricante. Aplicación de la ley extranjera y normativa comunitaria, Madrid, Marcial Pons, 1997.

Vilalta, A. E., MÉndez, R.M.: La responsabilidad extracontractual del fabricante, Barcelona, Bosch, 2001.

YzQuiERdo Tolsada, M.: La responsabilidad civil del profesional liberal. Teoría general, Madrid, Reus, 1989.

YzQuierdo Tolsada, M.: Sistema de responsabilidad civil, contractual y extracontractual, Madrid, Dykinson, 2001, págs. 327-342. 